\title{
Use of IFN-Based Biotherapeutics to Harness the Host Against Foot-And-Mouth Disease
}

\author{
Gisselle N. Medina ${ }^{1,2 *}$, Teresa de los Santos ${ }^{1 *}$ and Fayna Diaz-San Segundo ${ }^{1 *}$ \\ ${ }^{1}$ Plum Island Animal Disease Center (PIADC), ARS, USDA, Orient Point, NY, United States, ${ }^{2}$ Kansas State University, College \\ of Veterinary Medicine, Manhattan, KS, United States
}

\section{OPEN ACCESS}

Edited by:

Mariano Pérez-Filgueira,

National Agricultural Technology

Institute, Argentina

Reviewed by:

Margarita Sáiz,

Severo Ochoa Molecular Biology Center (CSIC-UAM), Spain

Kenneth James Genovese, Agricultural Research Service, United States Department of Agriculture, United States

${ }^{*}$ Correspondence:

Gisselle N. Medina

gisselle.medina@usda.gov

Teresa de los Santos

teresa.delossantos@usda.gov

Fayna Diaz-San Segundo

fayna.diaz-sansegundo@usda.gov

Specialty section:

This article was submitted to

Veterinary Infectious Diseases,

a section of the journal

Frontiers in Veterinary Science

Received: 17 April 2020

Accepted: 24 June 2020

Published: 11 August 2020

Citation:

Medina GN, de los Santos T and Diaz-San Segundo F (2020) Use of

IFN-Based Biotherapeutics to Harness the Host Against Foot-And-Mouth

Disease. Front. Vet. Sci. 7:465

doi: 10.3389/fvets.2020.00465
Foot-and-mouth disease (FMD) is a highly contagious vesicular disease of cloven-hoofed animals that severely constrains international trade of livestock and animal products. Currently, disease control measures include broad surveillance, enforcement of sanitary policy, and use of an inactivated vaccine. While use of these measures has contributed to eliminating foot-and-mouth disease virus (FMDV) from a vast area of the world, the disease remains endemic in three continents, and outbreaks occasionally appear in previously declared FMD-free zones, causing economic and social devastation. Among others, a very fast rate of viral replication and the need for 7 days to achieve vaccine-induced protection are the main limitations in controlling the disease. New fast-acting antiviral strategies targeted to boost the innate immunity of the host to block viral replication are needed. Here we review the knowledge on the multiple strategies FMDV has evolved to block the host innate immunity, with particularly focus on the past and current research toward the development of interferon (IFN)-based biotherapeutics in relevant livestock species.

Keywords: foot-and-mouth disease virus (FMDV), interferon (IFN), antivirals, biotherapeutics, IFN- $\alpha$, IFN- $\gamma$, IFN- $\lambda$, IFN- $\omega$

\section{INTRODUCTION}

\section{The Disease: Foot-And-Mouth Disease}

Foot-and-mouth disease (FMD) is one the most serious livestock diseases that affects cloven-hoofed animals including cattle, swine, sheep, and goats as well as numerous species of wild species (1). The disease displays high morbidity but is usually not lethal, except when it affects young animals that may develop myocarditis. Infected animals secrete copious amounts of virus particles before the onset of the clinical phase of the disease. Typical FMD clinical signs include fever and the appearance of vesicular lesions on the tongue, mouth, feet, and teats. Among ruminants that recovered from the disease, a relatively large number become asymptomatic virus carriers $(2,3)$, although it is not clear what is the contribution of these carrier animals to disease transmission in nature (4). The World Organization for Animal Health (OIE) lists FMD as a reportable disease and therefore, by law, participating nations are required to inform the organization about all FMD outbreaks. OIE member nations with reported cases of FMD are forbidden to engage in trading of FMD-susceptible animals or their products. Thus, the presence of FMD in a country can have severe economic consequences.

Different interventions to control an FMD outbreak include restriction of susceptible animal movement, slaughter of infected/contact animals, decontamination of infected and surrounding 
premises, and vaccination. Vaccination is an option used mostly in countries in which FMD is endemic, but disease-free nations prefer to abstain from such practice. In general, FMD-free countries that occasionally opted to vaccinate to better contain the outbreak did slaughter all vaccinated animals to regain commerce rights faster as occurred in the 2001 outbreak in the UK and the Netherlands $(5,6)$. The current approved FMD vaccine consists of purified chemically inactivated virus [binary ethylenimine (BEI)-treated] formulated with oil-based or aluminum adjuvants that induces serotype-specific protection in approximately 7 days, and it is applied with a boosting protocol for ensuring long-term protection (7). While this vaccine has been successfully used for many decades leading to disease eradication of a vast area of our planet, challenges remain. FMD is endemic in most of Africa and Asia, and occasionally epizootics appear in South America or in nations that have been disease-free for many years, as it happened in the UK, the Netherlands, South Korea, Taiwan, and Japan (8). Novel vaccine technologies have been developed, but to this end, none of them has fully addressed the limitations of the commercially available vaccine or is currently approved for massive use $(9,10)$. Alternatives or additional therapeutics that could complement, or in some instances substitute for vaccination protocols, include the use of antivirals and biotherapeutics that act quickly prior to induction of vaccine-induced immunity. The development of such molecules requires a thorough understanding of the biology of the virus and its intricate interactions particularly, with the innate immune molecular and cellular mechanisms evolved by the host.

\section{The Agent}

Foot-and-mouth disease virus (FMDV) is a member of the Aphthovirus genus within the Picornaviridae family, and it is the etiologic agent of FMD (1). The virus contains a single-stranded RNA of positive polarity. Its genome of $\sim 8,500$ nucleotides consists of a long open reading frame (ORF), flanked by a $5 /$ and a 3/-untranslated region (-UTR). The ORF encodes a polyprotein of about 2,300 amino acids which is processed by virus-encoded proteases. Processing results in the generation of precursors and mature protein products including: four structural [1A (VP4), 1B (VP2), 1C (VP3), 1D (VP1)] and ten non-structural (NS) proteins [L $\mathrm{L}^{\mathrm{pro}}, 2 \mathrm{~A}, 2 \mathrm{~B}, 2 \mathrm{C}, 3 \mathrm{~A}$, three distinct copies of $3 \mathrm{~B}(\mathrm{VPg}), 3 \mathrm{C}^{\text {pro }}$, and $3 \mathrm{D}^{\mathrm{pol}}$ ]. Due to high genetic variability, FMDV is categorized in seven distinct serotypes, A, Asia-1, C, O, and Southern African Territories 1-3 (SAT 1-3), and numerous subtypes or topotypes. Upon infection, the virus spreads very rapidly usually achieving $100 \%$ morbidity. Depending on the route of entry, less than 10 tissue culture infectious doses are required to infect and cause disease in animals (11). In fact, FMDV is one of the fastest replicating RNA viruses in nature, taking as little as 3$4 \mathrm{~h}$ to induce cytopathic effects in susceptible tissue culture cells. One could envisage that during FMDV replication, almost every component of the virus must play a role in dampening interfering cellular responses to allow such rapid virus replication.

\section{Innate Immunity and Interferon Activation}

Early protection against viral infection is fundamentally mediated by the action of interferons (IFNs), the pillar molecules of the innate immune system (12-14). Expression of IFN is triggered by the recognition of molecular signatures, collectively named pathogen-associated molecular patterns (PAMPs), via cellular receptors, pattern recognition receptors (PRRs) that can distinguish "self from non-self" molecules (Figure 1). Binding of PAMPs to PRRs triggers a series of signal transduction events and posttranslational modifications (PTMs: phosphorylation, ubiquitination, ISGylation, etc.) that ultimately activate latent transcription factors to induce IFN transcription. Subsequently, secreted IFN proteins bind to specific receptors on the plasma membrane to activate, in an autocrine and paracrine manner, discrete and overlapping cellular signal transduction pathways. Depending on the cell type and affected tissue, over 500 specific IFN-stimulated genes (ISGs) may be induced, many of which display antiviral activity to control the viral infection $(12,15,16)$. There are three families of IFNs based on the specific receptor usage: types I, II, and III (Table 1) (13, 43-50). Type I IFNs (i.e., IFN- $\alpha$ and IFN- $\beta$ ) signal through a heterodimeric receptor complex formed by IFNAR1/IFNAR2, type II IFN (IFN- $\gamma$ ) signals through the complex IFN $-\gamma \mathrm{R} 1 / \mathrm{IFN}-\gamma \mathrm{R} 2$, and type III IFNs bind the receptor complex IL-28R $\alpha /$ IL-10R $\beta$. Despite the receptor differences, the three IFN families transduce signals through the Janus kinase (JAK)-signal transducer and activator of transcription (STAT) pathway, and type I and type III IFNs induce redundant responses (Figure 2). Overall, the rapid production of IFN helps to limit viral replication while modulating other immune functions.

\section{FOOT-AND-MOUTH DISEASE VIRUS IMPAIRS INNATE IMMUNITY MOLECULAR INTERACTIONS}

Recognition of FMDV RNA by the host cell results in the establishment of a rapid antiviral state to limit and control infection. This selective pressure has allowed FMDV to evolve many strategies to ensure enhanced virulence and rapid infectivity. In general, RNA viruses can bypass the IFN response by blocking: (i) global cellular transcription and translation; (ii) IFN induction; and (iii) IFN signaling. Similarly to other RNA viruses, FMDV can also target IFN-independent antiviral responses mostly associated with cellular metabolic functions (i.e., autophagy, apoptosis, stress granule formation, etc.) that have been extensively described elsewhere $(51,52)$. In this section, we will summarize the current literature on studies conducted in vitro that explain how FMDV counteracts the host innate immune response at the molecular level, including RNA sensing, activation of adaptor/effector proteins, and regulation of signaling pathways by specific PTMs.

\section{Block on Cellular Transcription and Translation}

FMDV inhibition of cellular gene expression and protein synthesis during infection is mainly driven by the viralencoded proteases: Leader (Lpro) and 3C. FMDV Lpro is a papain-like protease (PLP) that induces cleavage of the translation initiation factor eIF4G, including eIF4GI and eIF4GII $(53,54)$ to disable cap-dependent protein synthesis. Also, FMDV Lpro causes degradation of the transcription factor 


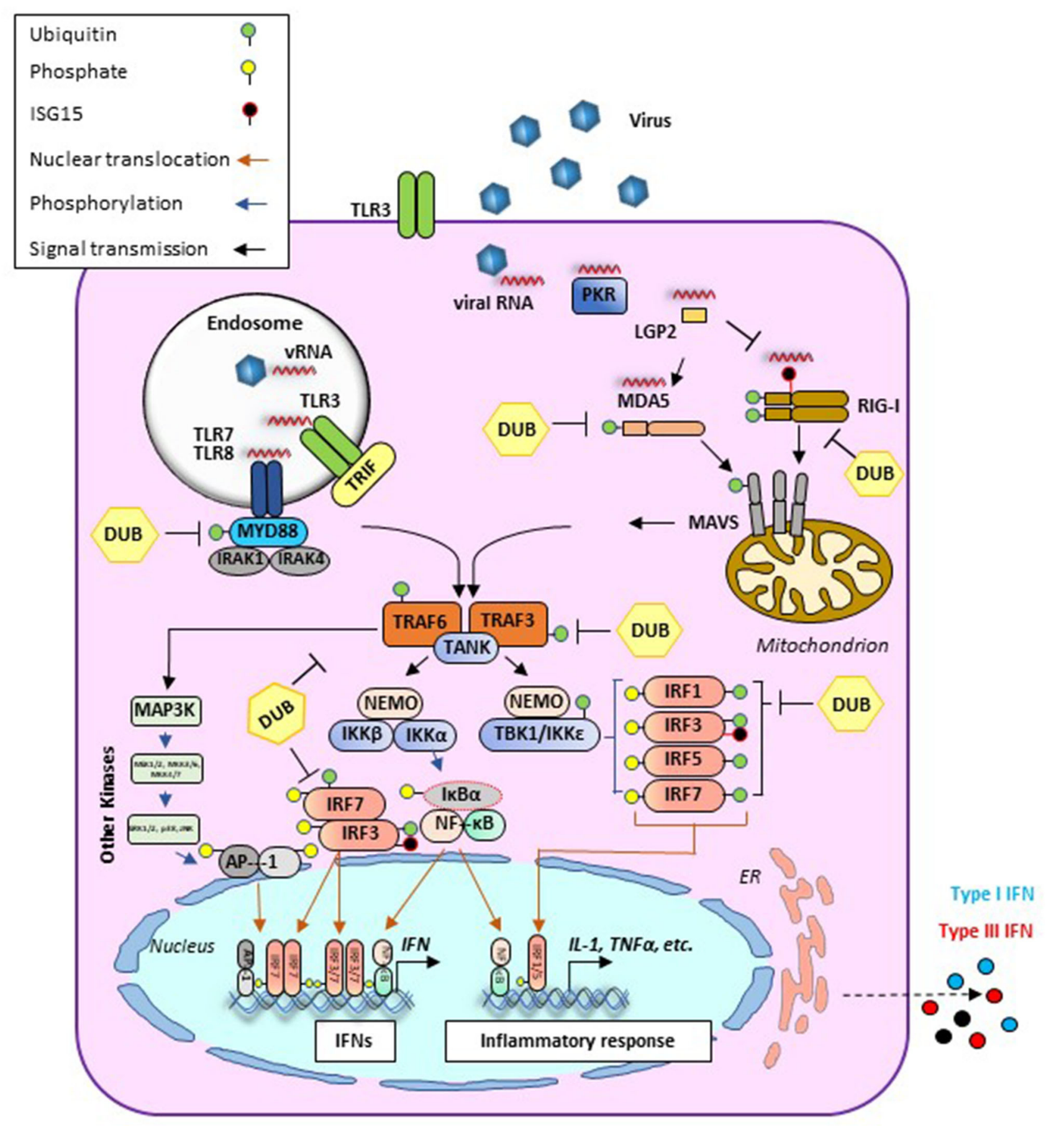

FIGURE 1 | Antiviral signaling pathways induced during viral infection. Cellular detection of microbial molecules known as pathogen-associated molecular patterns (PAMPs, i.e., viral RNA) is mediated by pattern recognition receptors (PRRs) including cytosolic RNA sensors (i.e., RIG-I, MDA-5, or LGP2) and/or membrane-bound TLRs. PAMP/PRR interaction activates signal transduction cascades (black arrows) that result in the production of IFN and inflammatory cytokines. RIG-I and MDA5 contain two caspase recruitment domains (CARD) and an RNA helicase domain. In the case of RIG-I, ubiquitination (green circles) is required for its effective activation. Activated signals from either RIG-I or MDA5 are transmitted downstream via the mitochondrial adaptor MAVS resulting in the formation of MAVS filaments. At this stage, different PTMs such as ubiquitination or ISGylation (black circles) can regulate their functions. Endosomal RNAs are detected by TLR3 or TLR7/8 which signal through adaptor proteins TRIF and MyD88, respectively. MyD88 uses other adaptors, IRAK1/4, to allow for interaction with TRAF proteins. In addition to their role as adaptor proteins, TRAFs also serve as E3 ubiquitin (Ub) ligases to regulate signaling. TRAF-mediated induction of poly-Ub is sensed by NEMO, thus recruiting downstream effector kinases such as TBK1 or IKK. These proteins form different signaling complexes (i.e., NEMO/TBK1 and NEMO/IKK), leading to phosphorylation (blue arrows) of transcription factors IRF3/7 (to a lesser extent IRF1 and IRF5 are also phosphorylated). IRF phosphorylation triggers dimerization and translocation 
FIGURE 1 | (orange arrows) to the nucleus where they bind mainly to IFN promoters/enhancers. Alongside with this pathway, TRAF6-E3 ligases can activate MAPK3 and other kinases including ERK1/2 and JNK which phosphorylate the components of the AP1 heterodimer, allowing for translocation to the nucleus and binding to the IFN $\beta$ promoter/enhancer to activate transcription. Activated IKK also phosphorylates IKB, releasing NF-kB, which then translocates to the nucleus and binds at the IFN $\beta$ promoter. AP-1, activating protein 1; CARD, caspase activation and recruitment domain; DUB, deubiquitinase; ER, endoplasmic reticulum; IKB, inhibitor of KB kinases; IKK, IKB kinase; IL, interleukin; IRAK, interleukin-1 receptor-associated kinase; IRF, IFN regulatory factor; LGP2, laboratory of genetics protein 2; MAPK, mitogen-activated protein kinase; MAVS, mitochondrial antiviral signaling protein; MDA5, melanoma differentiation-associated gene; MyD88, myeloid differentiation primary response protein 88d; NEMO, NF-kB essential modulator; NF-kB, nuclear factor-kB; PKR, protein kinase R; PTM, posttranslational modification; RIG-I, retinoic acid-inducible gene I; TANK, TRAF family member-associated NF-kB activator 1; TBK, TANK binding kinase; TLR, Toll-like receptor; TRAF, TNF receptor associated factor; TRIF, TIR-domain-containing adapter-inducing interferon- $\beta$.

TABLE 1 | Use of IFN-based therapies against FMDV.

\begin{tabular}{|c|c|c|c|c|c|}
\hline Type & Recept. & Signal & $\begin{array}{l}\text { Sub- } \\
\text { type }\end{array}$ & Species & Milestone \\
\hline \multirow[t]{9}{*}{ Type I } & IFNAR1/IFNAR2 & JAK1, TYK2 & IFN- $\alpha / \beta$ & Porcine/bovine $\bullet$ & $\begin{array}{l}\text { - Recombinant bacterial expressed IFN- } \alpha / \beta \text { is a potent biotherapeutic against } \\
\text { FMDV in vitro (17) }\end{array}$ \\
\hline & & & IFN- $\alpha$ & Porcine & $\begin{array}{l}\text { - Ad5 delivered polFN- } \alpha \text { protects swine against different serotypes of FMDV } \\
(18-20)\end{array}$ \\
\hline & & & & & $\begin{array}{l}\text { - polFN- } \alpha \text {-protection correlates with enhanced tissue-specific innate immune cell } \\
\text { infiltration in swine }(21,22)\end{array}$ \\
\hline & & & & & - polFN- $\alpha$ protection correlates with upregulation of essential ISGs in vitro $(23,24)$ \\
\hline & & & IFN- $\beta$ & Porcine & - Ad5 delivered porcine polFN- $\beta$ protects swine against FMDV (20) \\
\hline & & & IFN- $\delta$ & Porcine & - Bacterially expressed polFN- 88 significantly inhibits FMDV replication in vitro (25) \\
\hline & & & IFN- $\omega 7$ & Porcine & - E. coli produced polFN- $\omega 7$ protects cells against FMDV (26) \\
\hline & & & IFN- $\alpha \omega$ & Porcine & $\begin{array}{l}\text { - Bacterially expressed IFN- } \alpha \omega \text { added prior to infection resulted in a significant } \\
\text { reduction in FMDV replication in vitro (27) }\end{array}$ \\
\hline & & & IFN- $\tau$ & Ovine & - Ovine IFN- $\tau$ has antiviral effect against FMDV in vitro (28) \\
\hline \multirow[t]{2}{*}{ Type II } & 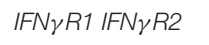 & JAK1, JAK2 & $I F N-\gamma$ & Bovine & - Recombinant bovine IFN- $\gamma$ reduced FMDV replication in BTY cell culture (29) \\
\hline & & & $I F N-\gamma$ & Porcine & - High dose of Ad5-polFN- $\gamma$ protects swine against FMD (30) \\
\hline \multirow[t]{3}{*}{ Type III } & IFN- $\lambda R 1 / / L-10 R 2$ & JAK2, TYK2 & IFN- $\lambda 1$ & Porcine & $\begin{array}{l}\text { - Replication of FMDV in IBRS-2 cells is inhibited by treatment with the purified } \\
\text { recombinant poIFN- } \lambda 1 \text { (31) }\end{array}$ \\
\hline & & & IFN- $\lambda 3$ & Bovine & $\begin{array}{l}\text { - Inoculation with Ad5-bolFN- } \lambda 3 \text { resulted in the induction of several ISGs in tissues } \\
\text { of the upper respiratory tract (32) and protected cattle against challenge with } \\
\text { FMDV (33) }\end{array}$ \\
\hline & & & & Porcine & - Ad5-polFN- $\lambda 3$ protects swine against challenge with FMDV (34) \\
\hline IFN Combos & & & $\begin{array}{l}\text { IFN- } \alpha \\
\text { IFN- } \gamma\end{array}$ & Porcine & $\begin{array}{l}\text { - Use of a combination of Ad5-polFN- } \gamma \text { and Ad5-polFN- } \alpha \text { (30) or Ad5-polFN- } \alpha \gamma \\
\text { (35) showed an enhancement of the antiviral activity against FMDV in swine }\end{array}$ \\
\hline \multirow[t]{4}{*}{ Other } & & & Poly IC & Porcine & $\begin{array}{l}\text { - Double stranded (ds) RNA poly ICLC, in combination with Ad5-polFN- } \alpha \\
\text { protected swine against FMDV (36) }\end{array}$ \\
\hline & & & SiRNA & Porcine & $\begin{array}{l}\text { - Combination of Ad5-polFN- } \alpha \gamma \text { with Ad-3siRNA targeting FMDV NS coding } \\
\text { regions blocked replication of all serotypes of FMDV in vitro (37) }\end{array}$ \\
\hline & & & IRF7/3 & Porcine & $\begin{array}{l}\text { - Inoculation with Ad5-IRF7/3(5D) resulted in induction of IFN- } \alpha \text { and fully protected } \\
\text { mice and swine challenged with FMDV } 1 \text { day after treatment }(38,39)\end{array}$ \\
\hline & & & IRES & Porcine & $\begin{array}{l}\text { - Use of synthetic IRES in combination with adjuvanted type-O FMD, improved } \\
\text { immune response and protection against FMDV challenge (40) }\end{array}$ \\
\hline \multirow[t]{3}{*}{$\begin{array}{l}\text { IFN/vaccine } \\
\text { combos }\end{array}$} & & & IFN- $\alpha$ & Porcine & $\begin{array}{l}\text { - Use of a combination of Ad5-po-IFN- } \alpha \text { and Ad5-A24 in swine resulted in } \\
\text { complete protection after challenge (19) }\end{array}$ \\
\hline & & & 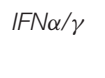 & Porcine & $\begin{array}{l}\text { - Ad5-polFN } \alpha / \gamma \text { co-administered with Ad5-siRNA targeting NS regions of FMDV, } \\
\text { and a commercial inactivated FMD vaccine partially protected swine (41) }\end{array}$ \\
\hline & & & IFN- $\lambda 3$ & Bovine & $\begin{array}{l}\text { - Use of a combination of Ad5-bov-IFN- } \gamma 3 \text { and Adt-O1M in cattle resulted in } \\
\text { complete protection after aerosol challenge (42) }\end{array}$ \\
\hline
\end{tabular}

nuclear factor (NF)- $\kappa \mathrm{B}$ and results in blockage of specific downstream signaling effectors $(55,56)$. Studies in porcine cells demonstrated that FMDV Lpro can promote its self-binding to the transcription factor activity-dependent neuroprotective protein (ADNP) and negatively regulate the activity of the IFN$\alpha$ promoter (57). In contrast, chromatin changes that favor the upregulation of IFN and ISGs can inhibit FMDV replication (58). Interestingly, deletion or mutations in different domains of Lpro result in viral attenuation in vitro and in vivo (5963). Furthermore, these studies have shown a strong type I IFN activity upon infection with different versions of FMDV Lpro mutants $(23,56,61)$. 


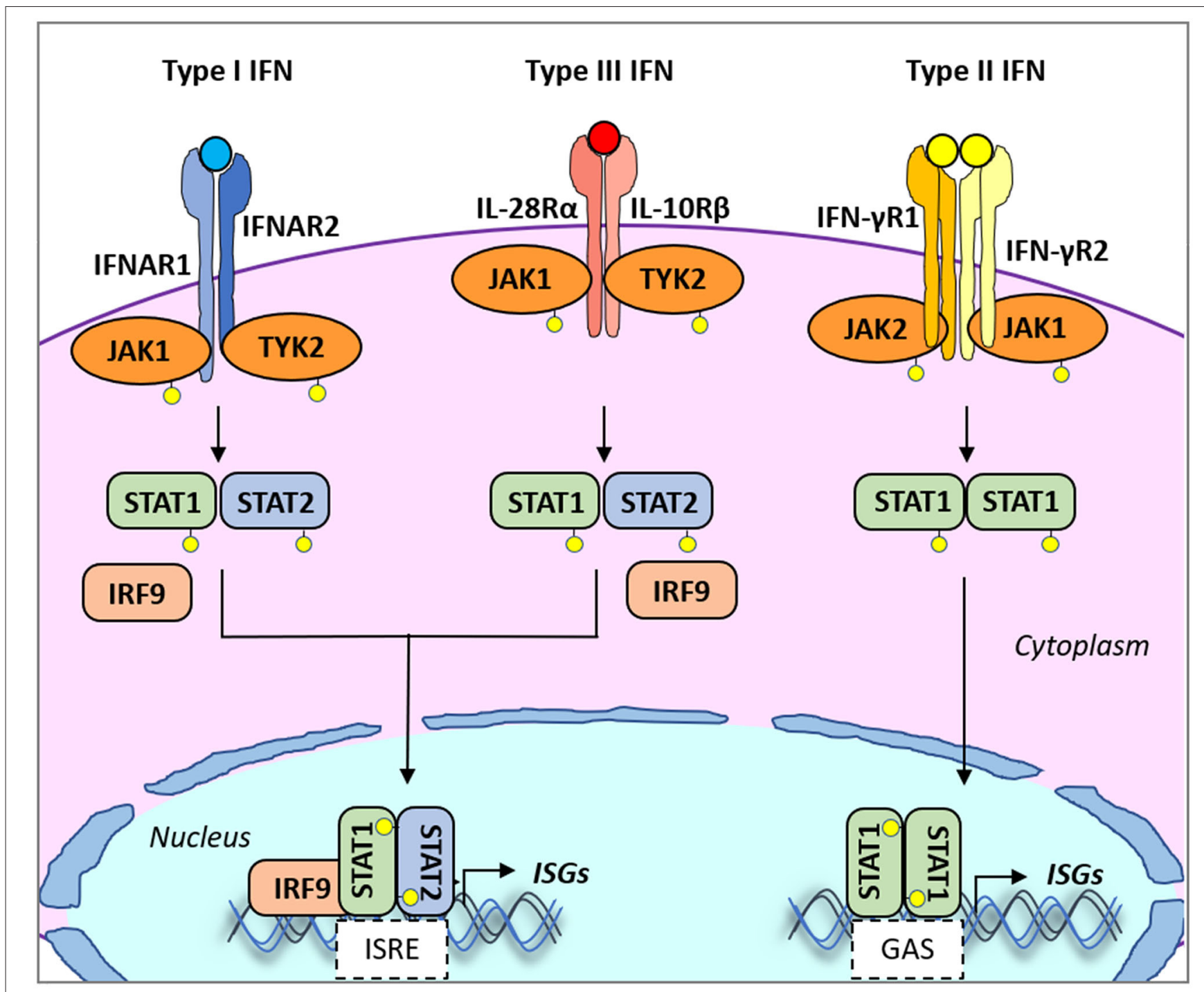

FIGURE 2 | Type I, II, and III interferon (IFN)-mediated signaling. All type I and type III IFN subtypes bind to respective receptors, IFNAR1/IFNAR2 and IFNLR1/LL10R2. These interactions trigger the phosphorylation of JAK1 and TYK2 kinases which in turn phosphorylate STAT1 and STAT2. JAK2 mediates type III IFN-dependent STAT phosphorylation. Phosphorylated heterodimers of STAT1/STAT2 bind to IRF9, forming the ISGF3G complex, which then translocates to the nucleus and binds to IFN-responsive elements (ISREs) present in the promoters of over 500 ISGs. Type II IFN binds to the heterodimeric IFN $\gamma$ R1/IFN $\gamma$ R2 receptor also inducing phosphorylation of JAK1/JAK2 kinases. In turn, mostly STAT1 is phosphorylated. Phosphorylated homodimers of STAT1 translocate to the nucleus and induce the expression of genes controlled by gamma-activated sequence (GAS)-dependent promoter sequences. IFNAR1/2, IFN alpha receptor1/2; IFN $\gamma$ R1/2, IFN-gamma receptor1/2; IFNALR1, IFN-lambda receptor 1; IL10R2, IL10 receptor 2; ISGs, IFN-stimulated genes; ISGF3G, ISG factor 3 gamma; JAK1/2, Janus kinase 1/2; STAT, signal transducer and activator of transcription.

Interruption of cellular translation during infection can also be mediated by FMDV 3Cpro, a chymotrypsin-like cysteine protease that similarly to Lpro targets eIF4G and the cap-binding complex eIF4A for cleavage, although these events occur later in the infection $(64,65)$. 3Cpro can also participate in the inhibition of host-cell transcription by cleaving histone H3 upon FMDV infection $(66,67)$.

\section{Block on Interferon Induction}

During infection, the initial event that leads to the production of IFN and pro-inflammatory cytokines is the recognition of viral RNA (Figure 1). Sensing of FMDV-RNA is mediated by MDA5 (68), a protein that belongs to a family of helicases known as retinoic acid-inducible gene-I (RIG-I)-like receptors (RLRs). Recent studies have shown that the interaction between RLRs (RIG-I and LGP2) and the FMDV proteins Lpro, 2B, and $3 \mathrm{~A}$ interferes with the induction of type I IFN (69-72). Indeed, overexpression of either FMDV $2 \mathrm{~B}$ or $3 \mathrm{~A}$ resulted in the downregulation of RIG-I and MDA5 mRNA expression $(69,70)$. In contrast, upregulation of LGP2 transcripts has been observed during FMDV infection in porcine cells, despite a detectable reduction of LGP2 protein levels, presumably due to FMDV 
Lpro-induced cleavage $(71,72)$. The apparent inconsistency between the levels of LGP2 mRNA and protein during FMDV infection may be explained by LGP2's ability to serve as a positive and negative regulator of RIG-I and MDA5 signaling, presumably affecting multiple steps of the IFN induction pathway (73). In addition to RLRs, nucleotide-binding oligomerization domain (NOD)-like receptors (NLRs), NOD1 and NOD2, also participate in the recognition of RNA. A study by Liu et al. (74) described the association of NOD2 with FMDV 2B, 2C, and 3Cpro to block innate immunity activation. Protein kinase $\mathrm{R}(\mathrm{PKR})$ is another recognized PRR that acts as an RNA sensor (75). Binding of RNA to PKR induces a conformational change that leads to autophosphorylation and activation (76). The primary target of activated PKR is the eukaryotic initiation factor $2 \alpha$ subunit (eIF $2 \alpha$ ), whose phosphorylation results in the blockage of cellular protein synthesis, a relatively common process during viral infection (77). Although no direct interaction between FMDV RNA and PKR has been demonstrated, it has been reported that PKR activity modulates FMDV infectivity. In fact, in tissue culture experiments, depletion of endogenous levels of PKR using siRNA resulted in increased FMDV titers $(17,23)$. Furthermore, it has been recently shown that overexpression of autophagyrelated ATG5-ATG12 proteins induces transcription of PKR and subsequent reduction of FMDV replication (78). These results suggest that PKR has a complex role as an RNA sensor but also as an antiviral agent during FMDV infection.

It has been demonstrated that FMDV also targets $\mathrm{DExD} / \mathrm{H}$ box RNA helicases, formally accepted as PRRs and modulators of the antiviral signaling pathway (79). In vitro experiments intending to analyze protein-protein interactions revealed the association between the RNA helicase DDX1 and FMDV 3D (80). Interestingly, these studies indicated that during FMDV infection in porcine cells, cleavage of DDX1 was detected, while overexpression of DDX1 resulted in the upregulation of IFN- $\beta$ and other ISG mRNAs which correlated with virus inhibition (80). Other DExD/H-box RNA helicases such as RNA helicase $\mathrm{H}$ (RHA) are hijacked during FMDV infection and interact with FMDV 5'UTR, 2C, and 3A to facilitate virus replication (81).

Signaling pathways downstream from RNA sensing involve the activation of different adaptor and effector proteins. One of the pathways that lead to signal activation requires the formation of specific complexes such as NF- $\kappa$ B essential modulator (NEMO) and the kinase IKK, which bridges the activation of NF- $\kappa \mathrm{B}$ and IFN regulatory factor (IRF) signaling pathways. It has been demonstrated that FMDV 3Cpro interacts with NEMO and induces its cleavage, resulting in impaired innate immune signaling (82). IRF-mediated signals driven by IRF-3 and IRF-7 can also be targeted by FMDV proteins. Specifically, overexpression of Lpro in PK-15 cells resulted in the downregulation of IRF-3 and IRF-7 protein levels and inactivation of IFN- $\beta$ and IFN- $\lambda 1$ promoter $(31,83)$.

Other factors involved in the activation of IFN include conventional PTMs such as phosphorylation and ubiquitination which ensure effective regulation of these signaling pathways (84). Also, different cellular deubiquitinases (DUBs) can reverse ubiquitination to control the intensity of the immune signaling response. Interestingly, it has been shown that FMDV Lpro can remove ubiquitin (Ub) molecules from several proteins required for IFN mRNA expression and those involved in the activation/repression of the IFN loop (85). This role became more evident by the observation that during infection, FMDV Lpro can cleave cellular substrates modified with the Ub-like molecule ISG15 (86). Furthermore, mutation of Lpro that impairs deISGylase/DUB function results in viral attenuation (87). In this regard, identification of FMDV targets for deubiquitination and deISGylation may contribute to elucidate the role of those factors in counteracting the innate response and develop novel countermeasures.

\section{Block on Interferon Signaling}

The ligand-mediated association of the specific IFN receptors promotes a signaling cascade that results in the phosphorylation of the receptor by the action of JAKs. These events result in the generation of docking sites for downstream adaptor and effector proteins including signal transducer and activator of transcription (STAT) proteins that associate with other factors and translocate to the nucleus inducing transcription of a plethora of ISGs (described above and in Figure 2). Although blockage of the JAK-STAT signaling pathway has not been reported during FMDV infection, overexpression of either FMDV 3Cpro or VP3 can inhibit this response. For instance, IFN- $\beta$-treated HeLa cells overexpressing FMDV 3Cpro suppressed IFN-stimulated promoter activities and induced proteasome- and caspase-independent protein degradation of karyopherin $\alpha 1$ (KPNA1), the nuclear localization signal receptor for tyrosine-phosphorylated STAT1 (88). This interaction inhibited the nuclear translocation of STAT1/STAT2, impeding maximal ISG promoter activity. In another study in HEK293T cells, overexpression of VP3 followed by coimmunoprecipitation revealed the association between VP3 and JAK1. FMDV VP3 also inhibited virus-triggered activation of the IFN- $\beta$ promoter, leading to the decrease in transcription of ISGs presumably due to lysosomal-induced degradation of JAK1 (89). A yeast two-hybrid screen identified FMDV 2C in complex with $\mathrm{N}$-myc and STAT interactor (Nmi), a protein known to augment immune function dependent on STAT-mediated transcription. Interestingly, such interaction resulted in the recruitment of Nmi to vesicular compartments followed by the induction of apoptosis in BHK-21 cells (90).

Evidently, FMDV proteins can also target crosstalk pathways induced by JAK/STAT signaling, and due to this versatility, understanding of these signaling events during FMDV infection is challenging.

\section{FOOT-AND-MOUTH DISEASE VIRUS IMPAIRS INTERFERON-MEDIATED CELLULAR INNATE IMMUNE RESPONSES}

Similarly to what happens in vitro, FMDV manipulates the early innate immune response in vivo to ensure a window of opportunity that favors viral replication and spread before 
the onset of effective adaptive immunity required for virus clearance. During infection, FMDV interacts with a range of host cells including natural killer (NK) cells, dendritic cells (DCs), monocytes $/ \mathrm{M} \phi$, and $\gamma \delta \mathrm{T}$ cells. All these cells play an important role in innate immune responses that trigger the production of large quantities of IFN and other cytokines which serve as autocrine agents (91-95).

Shortly after FMDV infection in swine, the number of circulating NK cells transiently decreases and the remaining NK cells show a dysfunctional lytic activity against target cells and a reduction of IFN- $\gamma$ production (96). In parallel, FMDV blocks the ability of porcine DCs to mature into conventional DCs (cDCs) (97), dampening their response against Toll-like receptor (TLR) ligands (98). Another subset of porcine DCs, plasmacytoid DCs (pDCs), also referred to as the major professional systemic IFN- $\alpha$ producers, are also affected by FMDV $(99,100)$. During infection, partial depletion of pDCs in the peripheral blood has been detected, and the remaining pDCs are less capable of producing IFN- $\alpha$ in response to ex vivo stimulation by TLR ligands or virus (101). Similar to pDCs, FMDV infection reduces the production of IFN- $\alpha$ on Langerhans cells (LCs) (98), a distinct subset of tissue-resident DCs of the skin (102). It has also been suggested that porcine $\gamma \delta \mathrm{T}$ cells and $\mathrm{M} \phi$ can serve as targets for FMDV infection in swine $(103,104)$, although the interplay between these cells and FMDV remains unclear.

Comparably to swine, FMDV infection in cattle triggers several early events in the innate immune system, although the effects are not exactly the same. For instance, bovine NK cells originated from FMDV-infected cows have an elevated cytotoxic function against bovine target cells in vitro (105). In addition, some subsets of cDCs are significantly decreased during the peak of viremia, while the expression of major histocompatibility complex (MHC) class II molecules on all bovine $\mathrm{CDCs}$ is reduced and the processing of exogenous antigen is impaired (106). Furthermore, during FMDV infection, the number of systemic mature bovine pDCs characterized by the expression of $\mathrm{CD} 4+$ and $\mathrm{MHC}$ class $\mathrm{II}+$ is increased presumably to intensify a humoral response and $\mathrm{T}$ cell activation, while levels of immature CD4+ MHC class II-pDCs are declined (106). Examination of bovine $\gamma \delta \mathrm{T}$ cells revealed that these cells with the surface expression marker $\mathrm{WC} 1+$ show a transient activated phenotype and increased expression of IFN- $\gamma(107)$.

FMDV also affects the innate immune response at the cytokine level in the natural host. In vivo cytokine profile analysis during the clinical phase of disease shows a systemic decrease of proinflammatory cytokines [IL-1 $\beta$, IL-6, and tumor necrosis factor (TNF) $\alpha]$ and an increase of the anti-inflammatory cytokine IL10 and IFN- $\alpha(22,33,61,101,106)$. Most likely, these changes are related to the early $\mathrm{T}$ cell unresponsiveness and lymphopenia described in swine and cattle during FMDV infection $(33,102$, 106, 108). Interestingly, a significant induction of inflammatory and antiviral factors at the local level is detected in cattle, in sites of abundant viral amplification, such as the nasal/oropharynx or vesicular lesions (109-111). A consistent upregulation of IFN- $\alpha$, $-\beta,-\gamma$, and $-\lambda$ mRNA in distinct microanatomical compartments of the nasopharyngeal mucosa, concurrent with occurrence of viremia, has also been detected in cattle (112). In contrast, studies in swine demonstrated that IFN expression in infected swine skin is inhibited (21). These differences may be due to the analysis of follicle-associated epithelium of the nasopharyngeal mucosa in cattle vs skin in swine or to the specific sampling technique used in each experiment. While in the cattle study laser-capture microscopy was used to focus only in areas of high FMDV replication, in the swine study, RNA was extracted from a piece of skin without discriminating between microanatomical compartments. Evidently, more studies are needed to elucidate the intricate interactions between FMDV and the innate immune system of specific animal hosts.

\section{EFFECTIVE USE OF INTERFERON AGAINST FOOT-AND-MOUTH DISEASE VIRUS IN VITRO}

\section{Type I Interferon}

The role of IFN in controlling FMDV replication was first proposed in 1962 when Dinter and Philipson demonstrated that calf kidney cells exposed to FMDV could become persistently infected and proposed this was a consequence of the induction of an IFN-like inhibitor present in the supernatant of infected cells (113). Later studies also suggested that swine leukocytes treated with phytohemagglutinin produced an inhibitor of FMDV replication with properties similar to IFN (114). It was not until 1999 that new studies demonstrated that the ability of FMDV to form plaques in cell culture correlated with the suppression of type I IFN $(\alpha / \beta)$ protein expression (115). These results were further supported by detection of IFN protein and antiviral activity in the supernatants of primary porcine, ovine, and bovine kidney cells infected with an attenuated FMDV mutant (leaderless) as compared to the supernatants of cells infected with wild-type (WT) virus. Later studies by the same group provided proof of concept on the use of recombinant bacterial expressed IFN- $\alpha / \beta$ as a potent biotherapeutic against FMDV (17). This approach was further developed by delivering recombinant porcine IFN- $\alpha / \beta$ using a replication-defective human Adenovirus 5 vector (Ad5-poIFN- $\alpha / \beta)$ (18). Infection of IBRS- 2 cells with Ad5-poIFN- $\alpha / \beta$ resulted in secreted poIFN$\alpha / \beta$ IFN protein detected as early as $4 \mathrm{~h}$ post-infection (hpi) and lasting for at least $30 \mathrm{~h}$. Most important, expressed IFN protein displayed strong biological antiviral activity against FMDV. Follow-up studies by the same group showed that all FMDV serotypes are very sensitive to Ad5-delivered poIFN- $\alpha / \beta$, and sterile protection could be achieved in vivo, highlighting the potential of this approach for the development into a broad biotherapeutic strategy to control FMDV replication (116).

In the last 10 years, advancements is genomics have led to the characterization of almost all type I IFN subtypes in the porcine and bovine genome (117-119), which are more numerous than those identified in primates and mice. This has revealed different functional genes and pseudogenes with diverse expression profiles and antiviral functions against different viruses, mostly in swine $(118,120,121)$. In fact, a recent study 
demonstrated that poIFN- $\omega 7$, known for its ability to induce the highest levels of antiviral activity when compared to other poIFN- $\omega$ subtypes, elicits an antiviral state against FMDV in IBRS- 2 cells treated with the recombinant form of poIFN- $\omega 7$ produced in Escherichia coli (26). Other subclasses of type I IFN, known to be produced in swine and cattle, include IFN alphaomega (IFN- $\alpha \omega$, also known as IFN- $\mu$ ) and IFN delta (IFN$\delta)$. Significant reduction in FMDV replication has been observed upon treatment of porcine cells with bacterially expressed IFN$\alpha \omega$ or IFN- $\delta 8$ prior to viral infection $(25,27)$.

Recently, another member of type I IFN family, IFN- $\tau$, which is only produced in ruminants, has been evaluated as an antiviral against FMDV (28). IFN- $\tau$ is a paracrine reproductive hormone secreted constitutively by trophoblasts and endometrial cells to increase the life span of the corpus luteum; however, production is not induced upon viral infection (122). While its secretion is restricted to ruminants, it has a broad-spectrum activity against various cross-species viruses. Interestingly, IFN- $\tau$ has $55 \%$ homology with the amino acids of IFN- $\alpha$, which allows for binding to type I IFN receptors. The property of IFN- $\tau$ that makes it an interesting therapeutic candidate for the treatment of various viral diseases is its significantly lower toxicity as compared to other type I IFNs.

\section{Type II Interferon}

In contrast to type I IFN, the type II IFN family is composed of only one member, IFN- $\gamma$, which exerts its actions through a specific receptor, IFNGR1/IFNGR2. IFN- $\gamma$ is weakly resistant to heat and acid, and it is able to activate leukocytes such as macrophages, and granulocytes, also exerting regulatory functions on T and B lymphocytes $(123,124)$. Indeed, production of IFN- $\gamma$ is used as a tool to measure cell-mediated immune responses against FMDV in vaccinated cattle (125-127) and in swine (61). Interestingly, IFN- $\gamma$ responses as measured by its ability to induce proliferation of CD4 $+\mathrm{T}$ cells correlate with a vaccine-induced protection and a reduction of FMDV persistence as it was shown for bovines inoculated with high doses of inactivated vaccine FMDV A Malaysia 97 (128). Therefore, the increase of the cellular immune response against FMDV seems to be comparable with the upregulation of IFN- $\gamma$ at least in cattle $(125,127,128)$.

One of the first experiments that examined the IFN- $\gamma$ potential to inhibit FMDV replication was performed in bovine thyroid (BTY) cells. BTY cells were treated with different concentrations of recombinant bovine IFN- $\gamma$ followed by infection with FMDV variants isolated from oropharynx cells collected from persistently infected bovines (29). Interestingly, IFN- $\gamma$ pretreatment resulted in a significant reduction of viral RNA and FMDV proteins as measured by RT-PCR and ELISA, respectively. These results were further bolstered by experiments intended to provide insights on the molecular mechanism of the IFN- $\gamma$ antiviral function against FMDV. Specifically, a transcriptomic analysis of FMDV-infected porcine kidney cells previously treated with IFN- $\gamma$ revealed a significant upregulation of transcription factors (STAT1 and IRF1) involved in the regulation of diverse ISGs (129). By using the Ad5 vector strategy, it was also demonstrated that type II IFN displays antiviral activity against FMDV in porcine cells (19). Interestingly, significant enhancement of the antiviral effect against FMDV was observed by using a combination of Ad5-poIFN- $\gamma$ and Ad5-poIFN- $\alpha$. Furthermore, use of a dicistronic Ad5 vector that expresses both poIFN- $\gamma$ and poIFN- $\alpha$ has shown enhanced antiviral activity in porcine cells (35).

\section{Type III Interferon}

The newest addition to the IFN families is the type III IFNs (IFN- $\lambda 1$ or IL29, IFN- $\lambda 2$ or IL $28 \mathrm{~A}$, IFN- $\lambda 3$ or IL $28 \mathrm{~B}$, and IFN- $\lambda 4$ ) which share signal transduction pathways of the type I IFN family albeit the use of a different cellular receptor, the IL-28R $\alpha /$ IL-10R $\beta$ heterodimer. In contrast to type I IFN receptors, which are expressed in almost all cell types, IL-28R $\alpha$ is expressed in a tissue-dependent fashion such as epithelia $(49,50)$. In addition, downstream activation of IFN- $\lambda$-induced signals requires phosphorylation of STAT1 mediated by JAK2 (130). The first study that reported the antiviral function of IFN- $\lambda$ against FMDV was conducted in bovine cell cultures (32). In this study, embryonic bovine kidney (EBK) cells treated with supernatants from cells previously transduced with Ad5-boIFN- $\lambda 3$ protected cells from FMDV-induced cytopathic effects and correlated with enhanced upregulation of IFN and ISG mRNAs. Similarly, porcine cells could be protected against FMDV infection by pretreatment with recombinant porcine IFN- $\lambda 1$ (poIFN- $\lambda 1$ ) (31) or with supernatants of cells transduced with an Ad5-poIFN$\lambda 3$ (34). All together, these results demonstrated that FMDV is highly susceptible to the action of type III IFN.

\section{EFFECTIVE USE OF INTERFERON AGAINST FOOT-AND-MOUTH DISEASE VIRUS IN THE NATURAL HOST}

Despite distinct induction of IFN and innate immune responses during FMDV infection in swine and cattle, spatial distribution of IFN is similar. In both species, in vivo detection of IFN occurs only after the virus has successfully replicated in the primary site and has spread systemically. In fact, similarly to what has been described in vitro (see previous section), the virus is very sensitive to the IFN antiviral effect in vivo (22). This property highlighted the potential use of these molecules as biotherapeutics against FMD, inviting new research to evaluate similar products against emerging animal diseases, a policy supported by the OIE. However, the use of IFNs in animals requires extensive testing in species of interest in order to evaluate the metabolic rate and potential adverse systemic effects of individual preparations (131-133). In this regard, although only in humans or animal models for human diseases, many approaches to change IFN's pharmacokinetic profile have been examined. These include the covalent modification of IFN with poly-ethylene-glycol (PEG) molecules (PEGylation) or the expression of recombinant IFN fused to Fc fragments of immunoglobulins. Evaluations of these modified IFNs have been tested for the treatment of multiple human diseases such as hepatitis B and C, multiple sclerosis, and cancer (134-137). Potential use of these new IFN-modified 
platforms should improve its biotherapeutic function in the animal setting.

In this section, we summarize in vivo studies that evaluated the use of different platforms to deliver IFN or IFN inducers, alone or in combination, as a means to protect against FMD (Table 1).

\section{Interferon Treatment Protects Swine Against Foot-And-Mouth Disease}

The first IFN tested in swine for its antiviral activity against FMDV was poIFN- $\alpha$, delivered with an Ad5 vector (18). Using this platform, swine intramuscularly (IM) inoculated with $10^{9}$ pfu of Ad5-poIFN- $\alpha$ expressed relatively high levels of systemic antiviral activity detectable as early as $6 \mathrm{hpi}$ and lasting for $72 \mathrm{~h}$. These results correlated with complete protection against intradermal (ID) challenge with FMDV A24 at 24 h post Ad5poIFN- $\alpha$ inoculation (18). Furthermore, complete protection lasted for 3-5 days, causing a delay in disease onset, reduced severity of clinical signs, and a significant reduction in viremia even when FMDV challenge was performed at 7 days post inoculation (dpi) or 1 day prior to the treatment (19). Extensive studies in swine using this vector or a modified proprietary version of Ad5 (Adt-poIFN, GenVec ${ }^{\circledR}$ ) demonstrated that delivery of poIFN- $\beta$ was also effective against challenge with FMDV at 1 dpi. Remarkably, depending on the administered Adt-poIFN dose, treated animals could be sterilely protected against FMD based on standardized parameters (20).

One of the advantages of using IFN against FMDV is the high likelihood for viral clearance regardless of the specific serotype (1, 138). In fact, swine experiments in which animals were inoculated with Ad5-pIFN- $\alpha$ and challenged intradermally (ID) $24 \mathrm{~h}$ later with different FMDV serotypes, A24, O1 Manisa or Asia, showed the same level of protection (20). Importantly, when the challenge was performed using a contact challenge, a route of inoculation that resembles the natural FMDV infection in swine (139-141), similar results were obtained (20).

Studies to understand the mechanisms of protection induced by type I IFN in swine demonstrated that protection of swine inoculated with Ad5-poIFN- $\alpha$ correlated with recruitment of partially mature skin DCs showing increased expression of CD80/86 and decreased phagocytic activity $(21,22)$. At the same time, an increase in the number of NK cells in draining lymph nodes was noticeable (21). These findings corresponded with upregulation of a number of ISGs, including PKR and 2/-5/-oligoadenylate synthase (OAS), which block FMDV replication in cell culture $(17,23)$. Other cytokines and chemokines, including monocyte chemotactic protein-1 (MCP-1), macrophage inflammatory protein (MIP)-1 $\alpha$, and IFN inducible protein 10 (IP-10) which are involved in chemoattraction of DCs and NK cells (142), were also upregulated. Interestingly, using a mouse model for FMDV (143), it was shown that IP-10 is necessary for protection conferred by murine IFN- $\alpha$ (muIFN- $\alpha)$, since C57Bl/6-IP-10 knockout mice treated with muIFN- $\alpha$ prior to challenge were not protected against disease, whereas $\mathrm{C} 57 \mathrm{Bl} / 6$-WT mice pretreated in the same way, were completely protected (24).
The effect of type II IFN has also been tested in swine using the Ad5 platform for delivery of IFN- $\gamma$ (30). Animals IM inoculated with $10^{10}$ pfu of Ad5-poIFN- $\gamma$ were protected against challenge at $1 \mathrm{dpi}$. Interestingly, enhanced antiviral activity was observed when a combination of Ad5-poIFN- $\alpha$ and Ad5-poIFN- $\gamma$ was administered, allowing for Ad5-IFN vector dose sparing to fully protect swine against challenge with FMDV A24 at 1 dpi (30). More recently, Kim et al. (35) used a similar approach against FMDV $\mathrm{O} 1$ in swine. Enhancement of potency against FMD was observed upon treatment with an Ad5 vector that expressed bicistronically poIFN- $\alpha$ and IFN- $\gamma$, as compared to either IFN alone (35).

The type III family of IFNs also has an antiviral effect against FMDV in vivo. Swine inoculated with Ad5-poIFN$\lambda 3$ and exposed 1 day later to FMDV by contact exposure to infected swine were completely protected from clinical disease, with no detectable viremia, viral RNA, or virus shedding (34). Interestingly, protection was achieved even when systemic antiviral activity or upregulation of ISGs in peripheral blood mononuclear cells (PBMCs) were undetected. This was consistent with previous reports indicating that expression of the IFN- $\lambda$ receptors (IFN- $\lambda$ R 1 ) and sensitivity to IFN- $\lambda$ are highest in epithelial tissues and not in leukocytes $(144,145)$.

Additional IFN-based therapeutics have been used in vivo in swine. These strategies were directed toward the use of synthetic nucleic acids that would mimic viral PAMPs or could interfere with the expression of specific viral genes without triggering the IFN response. In addition, construction of Ad5 vectors that deliver transcription factors or other antiviral factors involved in the production of IFN has been tested.

Use of nucleic acid-based molecules including the synthetic double-stranded polyriboinosinic-polyribocytidylic acid molecule stabilized with poly-L-lysine and carboxymethylcellulose (polyICLC) in combination with Ad5-poIFN- $\alpha$ protected swine against FMDV challenge as these animals developed the highest levels of antiviral activity along with detectable poIFN- $\alpha$ in the blood (36). This is in contrast with original studies done in pigs where intravenous inoculation of polyIC alone did not result in protection (146), highlighting the importance of the route of administration and immunity. Other studies have demonstrated that inoculation of mice with in vitro-transcribed RNAs mimicking some structural domains contained within the 5' and 3' non-coding FMDV UTRs can induce stable and robust production of systemic type I IFN (147). Moreover, the same group showed that delivery of a synthetic RNA, corresponding to 470 nt of the FMDV internal ribosome entry site (IRES), improves the immune response induced in mice in terms of timing, magnitude, and endurance of specific antibody titers (148). More recently, the same approach was evaluated in swine. Inoculation with the synthetic IRES transcript in combination with an adjuvanted type-O FMD vaccine resulted in an improved immune response and protection against FMDV challenge as compared to inoculation with the same vaccine alone (40). Interestingly, administration of this vaccine combination resulted in enhanced specific B and $\mathrm{T}$ cell-mediated immune responses as compared to suboptimal doses of the vaccine alone (40). 
Additionally, Ad5 delivery of small interfering RNAs (siRNAs) targeting FMDV structural and NS coding regions protected swine against FMDV (149), even when animals were treated 3 days after the challenge (150).

Due to the high mutation rate inherent to RNA viruses (151, 152), use of antivirals can result in virus adaptability. Studies by $\mathrm{Kim}$ et al. $(35,37,153)$ have proposed that the combination of antivirals including siRNA, viral polymerase inhibitors (i.e., ribavirin), and IFNs is better suited to minimize the generation of FMDV-resistant mutants. For instance, combination of Ad5poIFN- $\alpha / \gamma$ with an Ad5 expressing three different siRNAs (Ad53siRNA) targeting FMDV NS coding regions (2B and $3 \mathrm{C}$ ) was effective against all serotypes of FMDV in swine cells (37). Thus, a combined treatment with Ad5-poIFN- $\alpha / \gamma$ and Ad5-3siRNA could work as a fast-acting antiviral treatment to induce protection prior to the induction of vaccine-mediated adaptive immunity.

Another approach known to induce an early broad innate immune response is the use of replicon vaccine vector systems, such as the Venezuelan equine encephalitis virus (VEE) replicon particles (VRPs) (154). Treatment with this biotherapeutic platform results in the upregulation of a number of ISGs and the production of type I IFN protein (155) and has been tested successfully against FMDV in vitro and in vivo using a mouse model (24).

Baculovirus-based strategies have also proved successful in mice against FMD based on their robust IFN induction capacity. Molinari et al. (156) demonstrated that pretreatment of C57Bl/6 mice with a single injection of Autographa californica nuclear polyhedrosis virus (AcNPV) at $3 \mathrm{~h}$ or 3 days before FMDV challenge prevented animal death and decreased symptoms of disease and viremia. Further, treatment of mice with a combination of AcNPV and vaccine conferred early and full protection against lethal FMDV challenge (157).

More recently, a constitutively active transcription factor, IRF7/3(5D) fusion protein was explored as a means to induce innate responses against FMDV. In vivo delivery of IRF7/3 (5D) using the Ad5 vectored expression system resulted in potent induction of IFN- $\alpha$ and complete protection against FMDV in mice and swine $(38,39)$.

\section{Interferon Treatment Protects Cattle Against Foot-And-Mouth Disease}

Although the use of type I IFN using the Ad5 platform has been proven very successful in swine, preventive therapy only had limited efficacy in cattle. Inoculation of bovines with high doses of Ad5-poIFN- $\alpha$ or Ad5-bovine IFN- $\alpha$ (Ad5-boIFN- $\alpha$ ) induced a relatively low level of systemic antiviral activity (100$200 \mathrm{U} / \mathrm{ml}$ ), and challenge of these animals with FMDV A24 by intradermolingual (IDL) inoculation only resulted in a short delay and reduced severity of disease as compared to control animals (158).

In contrast, in preliminary experiments, the use of the type III IFN in bovine proved to be more successful than the use of type I IFN (32), although inoculation of cattle with Ad5-boIFN- $\lambda 3$ resulted in low levels of systemic antiviral activity. Interestingly, induction of several ISGs was detected in tissues of the upper respiratory tract, known targets of FMDV. An enhanced effect in ISG upregulation was detected when animals were treated with a combination of Ad5 vectors expressing type I and III IFNs. Inoculation of cattle with high doses of Ad5-boIFN- $\lambda 3$ followed by FMDV IDL challenge at 24 hpi resulted in a significant delay (6-12 days) and reduced severity of disease (33). Furthermore, a stronger effect was detected when treated cattle were challenged by aerosolization of FMDV using a method that best resembles the natural route of infection (140). No clinical signs of FMD, viremia, or viral shedding were found in the Ad5-boIFN- $\lambda 3$ treated animals for at least 9 days post-challenge, and one of three inoculated animals remained free of disease during the entire experiment (33). These results indicated that boIFN- $\lambda 3$ plays a critical role in the innate immune response of cattle against FMDV, and treatment with Ad5-boIFN- $\lambda 3$ is an effective biotherapeutic approach to control FMD in bovines.

\section{COMBINATION OF INTERFERON AND FOOT-AND-MOUTH DISEASE VACCINE AS AN APPROACH TO FULLY PROTECT LIVESTOCK AGAINST FOOT-AND-MOUTH DISEASE VIRUS}

A complete control strategy would ideally include both, a rapidacting approach to immediately limit disease spread, and a longlasting preventive measure to protect livestock from further exposure to FMDV. Therefore, it is reasonable to consider that a combination treatment of IFN and vaccine would be the best strategy to control FMD. In proof-of-concept studies in swine, a combination of Ad5-poIFN- $\alpha$ and an Ad5 vaccine that delivers structural and capsid processing proteins of FMDV A24 (Ad5-FMD-A24) resulted in complete protection when animals were challenged at 1-5 dpi while a strong adaptive immune response was induced (19). Using a comparable platform, a combination of Ad5-boIFN- $\lambda 3$ and Ad5-FMD-O1M had a similar performance in cattle. In this experiment, complete protection was achieved after animals were exposed to FMDV by aerosol (42). Remarkably, protection of animals treated with the combination occurred despite the absence of detectable neutralizing antibodies or antiviral activity in serum at the time of the challenge (42). Although not proved in this study, it is possible that the remaining antiviral activity at the mucosal level was able to block FMDV replication, as described for type III IFN during rotavirus infection (159). However, exploring other protective mechanisms such as cellular immunity should also be considered to understand this protection. Other strategies that have been explored in vivo include the simultaneous treatment with an Ad5 that delivers poIFN- $\alpha$ and FMDV VP1, but this study was performed in mice and it was not followed up with experiments in the natural FMDV host (160). More recently, You et al. (41) tested in swine the efficacy of the combined treatment with three antivirals, Ad5-poIFN $\alpha / \gamma$ coadministered with Ad5-siRNA, and a commercial inactivated FMD vaccine, however, only partial protection was observed 
when challenge was performed at 1, 2, or 7 days postvaccination (dpv) (41). All together, these results indicate that a combination treatment of IFN and vaccine is a desirable strategy that could be used to fully protect cattle and swine from FMD.

\section{CONCLUDING REMARKS AND FUTURE PERSPECTIVES}

Over the past 20 years, considerable progress has been made in the development of IFN-based biotherapeutics to control FMD. The use of different delivery technologies, such as the Ad5 vector, highlighted the ability of IFN to confer protective immunity against FMDV in swine and cattle. Importantly, the identification of different cellular factors and cellular immune responses that are targeted during FMDV infection and affect the IFN system furnished our knowledge of FMDV virulence and pathogenesis. These discoveries permitted the development of new intervention strategies to improve IFN-based therapies such as proper selection of IFN type, evaluation of the route and site of inoculation, and utilization of synthetic IFN inducers that could act as potential adjuvants, augmenting the intrinsic biotherapeutic effect, and also improving FMD vaccine performance. Such strategies seem ideal for application in endemic regions to potentially reduce the number of exposed or at high risk of exposure animals. On the other hand, a similar strategy could be applied in the unfortunate event of outbreaks in FMD-free countries that opt for a vaccination-to-kill policy. In this case, by using an antiviral/vaccine combination approach, disease spread would be more limited, hopefully reducing the economic burden.

\section{REFERENCES}

1. Grubman M, Baxt B. Foot-and-mouth disease. Clin Microbiol Rev. (2004) 17:465-93. doi: 10.1128/CMR.17.2.465-493.2004

2. Maree F, de Klerk-Lorist L-M, Gubbins S, Zhang F, Seago J, PérezMartín E, et al. Differential persistence of foot-and-mouth disease virus in african buffalo is related to virus virulence. J Virol. (2016) 90:5132-40. doi: 10.1128/JVI.00166-16

3. Arzt J, Belsham GJ, Lohse L, Bøtner A, Stenfeldt C. Transmission of foot-and-mouth disease from persistently infected carrier cattle to naive cattle via transfer of oropharyngeal fluid. mSphere. (2018) 3:e00365-18. doi: $10.1128 / \mathrm{mSphere} .00365-18$

4. Stenfeldt C, Arzt J. The carrier conundrum; a review of recent advances and persistent gaps regarding the carrier state of foot-and-mouth disease virus. Pathogens. (2020) 9:167. doi: 10.3390/pathogens9030167

5. Pluimers FH, Akkerman AM, van der Wal P, Dekker A, Bianchi A. Lessons from the foot and mouth disease outbreak in The Netherlands in 2001. Rev Sci Tech. (2002) 21:711-21. doi: 10.20506/rst.21.3.1371

6. Scudamore JM, Harris DM. Control of foot and mouth disease: lessons from the experience of the outbreak in Great Britain in 2001. Rev Sci Tech L. (2002) 21:699-710. doi: 10.20506/rst.21.3.1351

7. Doel TR. FMD vaccines. Virus Res. (2003) 91:81-99. doi: 10.1016/S0168-1702(02)00261-7

8. Knight-Jones TJD, Robinson L, Charleston B, Rodriguez LL, Gay CG, Sumption KJ, et al. Global foot-and-mouth disease research update and gap analysis: 2 - epidemiology, wildlife and economics. Transb Emerg Dis. (2016) 63:14-29. doi: 10.1111/tbed.12522
However, before IFNs could be used as a gold standard therapeutic agent against FMD, several considerations must be taken. For instance, metabolic rate of absorption and toxicity should be carefully evaluated to finely tune therapeutic doses for each animal species of interest. Study of specific IFN expression profiles and intrinsic antiviral activities in different tissues may also help to improve and optimize treatments for specific animal hosts.

Some of these shortcomings could be aided by selecting the right type and subtype of IFN, depending of the specific animal species of interest. In addition, novel advancements in protein engineering have demonstrated that IFN potency and bioavailability could be improved. In this regard, chemically modified IFN molecules (i.e., PEGylation) or other protein fusions deserve being evaluated as possible interventions for animal diseases. Finally, continuing studies to better characterize innate immune responses during FMDV infection in vitro and in vivo will help refine our understanding of the anti-FMDV properties of IFN and hopefully develop improved therapeutics for effective FMD control and disease eradication.

\section{AUTHOR CONTRIBUTIONS}

All authors contributed equally with literature searches, writing, editing, and approving the submission.

\section{FUNDING}

This work was funded by USDA ARS-CRIS Project 1940-32000061-00D and USDA agreement 58-8064-8-010 with Kansas State University.

9. Diaz-San Segundo F, Medina GN, Stenfeldt C, Arzt J, de los Santos T. Foot-and-mouth disease vaccines. Vet Microbiol. (2017) 206:102-12. doi: 10.1016/j.vetmic.2016.12.018

10. de los Santos T, Diaz-San Segundo F, Rodriguez LL. The need for improved vaccines against foot-and-mouth disease. Curr Opin Virol. (2018) 29:16-25. doi: 10.1016/j.coviro.2018.02.005

11. Alexandersen S, Quan M, Murphy C, Knight J, Zhang Z. Studies of quantitative parameters of virus excretion and transmission in pigs and cattle experimentally infected with foot-and-mouth disease virus. J Comp Pathol. (2003) 129:268-82. doi: 10.1016/S0021-9975(03)00045-8

12. Schoggins JW, Rice CM. Interferon-stimulated genes and their antiviral effector functions. Curr Opin Virol. (2011) 1:519-25. doi: 10.1016/j.coviro.2011.10.008

13. Fensterl V, Chattopadhyay S, Sen GC. No love lost between viruses and interferons. Annu Rev Virol. (2015) 2:549-72. doi: 10.1146/annurev-virology-100114-055249

14. Mesev EV, LeDesma RA, Ploss A. Decoding type I and III interferon signalling during viral infection. Nat Microbiol. (2019) 4:914-24. doi: 10.1038/s41564-019-0421-x

15. Schneider WM, Chevillotte MD, Rice CM. Interferon-stimulated genes: a complex web of host defenses. Annu Rev Immunol. (2014) 32:513-45. doi: 10.1146/annurev-immunol-032713-120231

16. Chow KT, Gale M, Loo Y-M. RIG-I and other RNA sensors in antiviral immunity. Annu Rev Immunol. (2018) 36:667-94. doi: 10.1146/annurev-immunol-042617-053309

17. Chinsangaram J, Koster M, Grubman MJ. Inhibition of L-deleted footand-mouth disease virus replication by alpha/beta interferon involves 
double-stranded RNA-dependent protein kinase. J Virol. (2001) 75:5498503. doi: 10.1128/JVI.75.12.5498-5503.2001

18. Chinsangaram J, Moraes MP, Koster M, Grubman MJ. Novel viral disease control strategy: adenovirus expressing alpha interferon rapidly protects swine from foot-and-mouth disease. J Virol. (2003) 77:1621-5. doi: 10.1128/JVI.77.2.1621-1625.2003

19. Moraes MP, Chinsangaram J, Brum MCS, Grubman MJ. Immediate protection of swine from foot-and-mouth disease: a combination of adenoviruses expressing interferon alpha and a foot-andmouth disease virus subunit vaccine. Vaccine. (2003) 22:268-79. doi: 10.1016/S0264-410X(03)00560-7

20. Dias C. CA, Moraes MP, Diaz-SanSegundo F, de los Santos T, Grubman MJ. Porcine type I interferon rapidly protects swine against challenge with multiple serotypes of foot-and-mouth disease virus. J Interferon Cytok Res. (2011) 31:227-36. doi: 10.1089/jir.2010.0055

21. Diaz-San Segundo F, Moraes MP, de Los Santos T, Dias CC. A, Grubman MJ. Interferon-induced protection against foot-and-mouth disease virus infection correlates with enhanced tissue-specific innate immune cell infiltration and interferon-stimulated gene expression. J Virol. (2010) 84:2063-77. doi: 10.1128/JVI.01874-09

22. Diaz-San Segundo F, Montiel N, de los Santos T, Grubman MJ. Understanding the Mechanisms of Interferon-Induced Protection Against Foot-and-Mouth Disease. Virology II - Advanced Issues. ISBN: 978-1922227-45-4. iConcept Press (2013).

23. de los Santos T, De Avila Botton S, Weiblen R, Grubman MJ. The leader proteinase of foot-and-mouth disease virus inhibits the induction of beta interferon mRNA and blocks the host innate immune response. $J$ Virol. (2006) 80:1906-14. doi: 10.1128/JVI.80.4.1906-1914.2006

24. Diaz-San Segundo F, Dias CCA, Moraes MP, Weiss M, Perez-Martin E, Owens G, et al. Venezuelan equine encephalitis replicon particles can induce rapid protection against foot-and-mouth disease virus. J Virol. (2013) 87:5447-60. doi: 10.1128/JVI.03462-12

25. Li SF, Shao JJ, Zhao FR, Gong MJ, Xie YL, Chang HY, et al. Antiviral activity of porcine interferon delta 8 against foot-and-mouth disease virus in vitro. Int Immunopharmacol. (2018) 59:47-52. doi: 10.1016/j.intimp.2018.03.022

26. Li SF, Zhao FR, Gong MJ, Shao JJ, Xie YL, Chang HY, et al. Antiviral activity of porcine interferon omega 7 against foot-and-mouth disease virus in vitro. J Med Virol. (2019) 91:208-14. doi: 10.1002/jmv.25272

27. Li SF, Gong MJ, Xie YL, Shao JJ, Zhao FR, Zhang YG, et al. A novel type I interferon, interferon alphaomega, shows antiviral activity against foot-and-mouth disease virus in vitro. Microb Pathog. (2019) 127:79-84. doi: 10.1016/j.micpath.2018.11.040

28. Usharani J, Park SY, Cho EJ, Kim C, Ko YJ, Tark D, et al. Antiviral activity of ovine interferon tau 4 against foot-and-mouth disease virus. Antiviral Res. (2017) 143:134-41. doi: 10.1016/j.antiviral.2017.01.018

29. Zhang ZD, Hutching G, Kitching P, Alexandersen S. The effects of gamma interferon on replication of foot-and-mouth disease virus in persistently infected bovine cells. Arch Virol. (2002) 147:2157-67. doi: 10.1007/s00705-002-0867-6

30. Moraes MP, de Los Santos T, Koster M, Turecek T, Wang H, Andreyev VG, et al. Enhanced antiviral activity against foot-and-mouth disease virus by a combination of type I and II porcine interferons. J Virol. (2007) 81:7124-35. doi: 10.1128/JVI.02775-06

31. Wang D, Fang L, Liu L, Zhong H, Chen Q, Luo R, et al. Footand-mouth disease virus (FMDV) leader proteinase negatively regulates the porcine interferon- $\lambda 1$ pathway. Mol Immunol. (2011) 49:407-12. doi: 10.1016/j.molimm.2011.09.009

32. Díaz-San Segundo F, Weiss M, Perez-Martín E, Koster MJ, Zhu J, Grubman MJ, et al. Antiviral activity of bovine type III interferon against foot-and-mouth disease virus. Virology. (2011) 413:283-92. doi: 10.1016/j.virol.2011.02.023

33. Perez-Martin E, Weiss M, Diaz-San Segundo F, Pacheco JM, Arzt J, Grubman MJ, et al. Bovine type III interferon significantly delays and reduces the severity of foot-and-mouth disease in cattle. J Virol. (2012) 86:4477-87. doi: 10.1128/JVI.06683-11

34. Perez-Martin E, Diaz-San Segundo F, Weiss M, Sturza DF, Dias CC, RamirezMedina E, et al. Type III interferon protects swine against foot-and-mouth disease. J Interferon Cytokine Res. (2014) 34:1-12. doi: 10.1089/jir.2013.0112
35. Kim SM, Kim SK, Park JH, Lee KN, Ko YJ, Lee HS, et al. A recombinant adenovirus bicistronically expressing porcine interferon- $\alpha$ and interferon$\gamma$ enhances antiviral effects against foot-and-mouth disease virus. Antiviral Res. (2014) 104:52-8. doi: 10.1016/j.antiviral.2014.01.014

36. Dias CC, Moraes MP, Weiss M, Segundo FD-S, Perez-Martin E, Salazar AM, et al. Novel antiviral therapeutics to control foot-and-mouth disease. J Interf Cytokine Res. (2012) 32:462-73. doi: 10.1089/jir.2012.0012

37. Kim SM, Park JH, Lee K, Kim SK, You SH, Tark D, et al. Robust protection against highly virulent foot-and-mouth disease virus in swine by combination treatment with recombinant adenoviruses expressing porcine interferon- $\alpha \gamma$ and multiple small interfering RNAs. J Virol. (2015) 89:826779. doi: 10.1128/JVI.00766-15

38. Ramirez-Carbajal L, Diaz-SanSegundo F, Hickman D, Long CR, Zhu J, Rodriguez LL, et al. Expression of porcine fusion protein irf7/3(5d) efficiently controls foot-and-mouth disease virus replication. J Virol. (2014) 88:1114053. doi: 10.1128/JVI.00372-14

39. Ramírez-Carbajal L, Diaz-San Segundo F, Ramirez-Medina E, Rodríguez LL, de los Santos T. Constitutively active IRF7/IRF3 fusion protein completely protects swine against foot-and-mouth disease. J Virol. (2016) 90:8809-21. doi: 10.1128/JVI.00800-16

40. Borrego B, Blanco E, Rodriguez-Pulido M, Mateos F, Lorenzo G, Cardillo S, et al. Combined administration of synthetic RNA and a conventional vaccine improves immune responses and protection against foot-and-mouth disease virus in swine. Antiviral Res. (2017) 142:30-36. doi: 10.1016/j.antiviral.2017.03.009

41. You SH, Kim T, Choi JH, Park G, Lee KN, Kim B, et al. Coinjection of a vaccine and anti-viral agents can provide fast-acting protection from foot-and-mouth disease. Antiviral Res. (2017) 143:195-204. doi: 10.1016/j.antiviral.2017.04.009

42. Diaz-San Segundo F, Montiel NA, Sturza DF, Perez-Martin E, Hickman D, Ramirez-Medina E, et al. Combination of Adt-O1Manisa and Ad5-boIFN $\lambda 3$ induces early protective immunity against foot-and-mouth disease in cattle. Virology. (2016) 499:340-9. doi: 10.1016/j.virol.2016.09.027

43. Henke A, Zell R, Ehrlich G, Stelzner A. Expression of immunoregulatory cytokines by recombinant coxsackievirus B3 variants confers protection against virus-caused myocarditis. J Virol. (2001) 75:8187-94. doi: 10.1128/JVI.75.17.8187-8194.2001

44. Samuel CE. Antiviral actions of interferons. Clin Microbiol Rev. (2001) 14:778-809. doi: 10.1128/CMR.14.4.778-809.2001

45. Basler CF, Garcia-Sastre A. Viruses and the type I interferon antiviral system: induction and evasion. Int Rev Immunol. (2002) 21:305-37. doi: 10.1080/08830180213277

46. Frese M, Schwärzle V, Barth K, Krieger N, Lohmann V, Mihm S, et al. Interferon- $\gamma$ inhibits replication of subgenomic and genomic hepatitis C virus RNAs. Hepatology. (2002) 35:694-703. doi: 10.1053/jhep.2002. 31770

47. Ank N, West H, Paludan SR. IFN-lambda: novel antiviral cytokines. $J$ Interferon Cytok Res. (2006) 26:373-9. doi: 10.1089/jir.2006.26.373

48. Shrestha B, Wang T, Samuel MA, Whitby K, Craft J, Fikrig E, et al. Gamma interferon plays a crucial early antiviral role in protection against West Nile virus infection. J Virol. (2006) 80:5338-48. doi: 10.1128/JVI.00274-06

49. Sheppard P, Kindsvogel W, Xu W, Henderson K, Schlutsmeyer S, Whitmore TE, et al. IL-28, IL-29 and their class II cytokine receptor IL-28R. Nat Immunol. (2003) 4:63-8. doi: 10.1038/ni873

50. Kotenko SV, Gallagher G, Baurin VV, Lewis-Antes A, Shen M, Shah NK, et al. IFN-lambdas mediate antiviral protection through a distinct class II cytokine receptor complex. Nat Immunol. (2003) 4:69-77. doi: 10.1038/ni875

51. Medina GN, Segundo FDS, Stenfeldt C, Arzt J, de los Santos T. The different tactics of foot-and-mouth disease virus to evade innate immunity. Front Microbiol. (2018) 9:2644. doi: 10.3389/fmicb.2018.02644

52. Sun D, Wen X, Wang M, Mao S, Cheng A, Yang X, et al. Apoptosis and autophagy in picornavirus infection. Front Microbiol. (2019) 10:2032. doi: $10.3389 /$ fmicb.2019.02032

53. Medina M, Domingo E, Brangwyn JK, Belsham GJ. The two species of the foot-and-mouth disease virus leader protein, expressed individually, exhibit the same activities. Virology. (1993) 194:355-9. doi: 10.1006/viro.1993.1267

54. Gradi A, Foeger N, Strong R, Yuri V, Sonenberg N, Skern T, et al. Cleavage of eukaryotic translation initiation factor 4GII within foot-and-mouth disease 
virus-infected cells : identification of the L-protease cleavage site in vitro. J Virol. (2004) 78:3271-8. doi: 10.1128/JVI.78.7.3271-3278.2004

55. de los Santos T, Diaz-San Segundo F, Grubman MJ. Degradation of nuclear factor kappa B during foot-and-mouth disease virus infection. J Virol. (2007) 81:12803-15. doi: 10.1128/JVI.01467-07

56. Zhu J, Weiss M, Grubman MJ, de los Santos T. Differential gene expression in bovine cells infected with wild type and leaderless foot-and-mouth disease virus. Virology. (2010) 404:32-40. doi: 10.1016/j.virol.2010.04.021

57. Medina GN, Knudsen GM, Greninger AL, Kloc A, Díaz-San Segundo F, Rieder E, et al. Interaction between FMDV Lpro and transcription factor ADNP is required for optimal viral replication. Virology. (2017) 505:12-22. doi: 10.1016/j.virol.2017.02.010

58. Singh N, Ramirez-Carvajal L, de los Santos T, Golding MC, Long CR. Inhibition of EHMT2 induces a robust antiviral response against foot-andmouth disease and vesicular stomatitis virus infections in bovine cells. J Interf Cytok Res. (2016) 36:37-47. doi: 10.1089/jir.2015.0006

59. Piccone ME, Rieder E, Mason PW, Grubman MJ. The foot-and-mouth disease virus leader proteinase gene is not required for viral replication. $J$ Virol. (1995) 69:5376-82. doi: 10.1128/JVI.69.9.5376-5382.1995

60. Mason PW, Piccone ME, Mckenna TS, Chinsangaram J, Grubman MJ. Evaluation of a live-attenuated foot-and-mouth disease virus as a vaccine candidate. Virology. (1997) 227:96-102. doi: 10.1006/viro.1996.8309

61. Diaz-San Segundo F, Weiss M, Pérez-Martín E, Dias CC, Grubman MJ, Santos TDL. Inoculation of swine with foot-and-mouth disease SAP-mutant virus induces early protection against disease. J Virol. (2012) 86:1316-27. doi: 10.1128/JVI.05941-11

62. Eschbaumer M, Dill V, Carlson JC, Arzt J, Stenfeldt C, Krug PW, et al. Foot-and-mouth disease virus lacking the leader protein and containing two negative DIVA markers (FMDV LL3B3D A24) is highly attenuated in pigs. Pathogens. (2020) 9:129. doi: 10.3390/pathogens9020129

63. de los Santos T, Segundo FD-S, Zhu J, Koster M, Dias CCA, Grubman MJ. A conserved domain in the leader proteinase of foot-and-mouth disease virus is required for proper subcellular localization and function. J Virol. (2009) 83:1800-10. doi: 10.1128/JVI.02112-08

64. Belsham GJ, McInerney GM, Ross-Smith N. Foot-and-mouth disease virus $3 \mathrm{C}$ protease induces cleavage of translation initiation factors eIF4A and eIF4G within infected cells. J Virol. (2000) 74:272-80. doi: 10.1128/JVI.74.1.272-280.2000

65. Li W, Ross-Smith N, Proud CG, Belsham GJ. Cleavage of translation initiation factor 4AI (eIF4AI) but not eIF4AII by foot-and-mouth disease virus 3C protease: Identification of the eIF4AI cleavage site. FEBS Lett. (2001) 507:1-5. doi: 10.1016/S0014-5793(01)02885-X

66. Falk MM, Grigera PR, Bergmann IE, Zibert A, Multhaup G, Beck E. Foot-and-mouth disease virus protease $3 \mathrm{C}$ induces specific proteolytic cleavage of host cell histone H3. J Virol. (1990) 64:748-56. doi: 10.1128/JVI.64.2.748-756.1990

67. Tesar M, Marquardt O. Foot-and-mouth disease virus protease 3C inhibits cellular transcription and mediates cleavage of histone H3. Virology. (1990) 174:364-74. doi: 10.1016/0042-6822(90)90090-E

68. Hüsser L, Alves MP, Ruggli N, Summerfield A. Identification of the role of RIG-I, MDA-5 and TLR3 in sensing RNA viruses in porcine epithelial cells using lentivirus-driven RNA interference. Virus Res. (2011) 159:9-16. doi: 10.1016/j.virusres.2011.04.005

69. Li D, Lei C, Xu Z, Yang F, Liu H, Zhu Z, et al. Foot-and-mouth disease virus non-structural protein $3 \mathrm{~A}$ inhibits the interferon- $\beta$ signaling pathway. $S c i$ Rep. (2016) 6:21888. doi: 10.1038/srep21888

70. Zhu Z, Wang G, Yang F, Cao W, Mao R, Du X, et al. Foot-andmouth disease virus viroporin $2 \mathrm{~B}$ antagonizes RIG-I-mediated antiviral effects by inhibition of its protein expression. J Virol. (2016) 90:11106-21. doi: 10.1128/JVI.01310-16

71. Zhu Z, Li C, Du X, Wang G, Cao W, Yang F, et al. Foot-and-mouth disease virus infection inhibits LGP2 protein expression to exaggerate inflammatory response and promote viral replication. Cell Death Dis. (2017) 8:e2747. doi: $10.1038 /$ cddis. 2017.170

72. Rodríguez-Pulido M, Sánchez-Aparicio MT, Martínez-Salas E, García-Sastre A, Sobrino F, Sáiz M. Innate immune sensor LGP2 is cleaved by the Leader protease of foot-and-mouth disease virus. PLOS Pathog. (2018) 14:1-21. doi: 10.1371/journal.ppat.1007135
73. Tan X, Sun L, Chen J, Chen ZJ. Detection of microbial infections through innate immune sensing of nucleic acids. Annu Rev Microbiol. (2018) 72:44778. doi: 10.1146/annurev-micro-102215-095605

74. Liu H, Zhu Z, Xue Q, Yang F, Cao W, Zhang K, et al. Foot-and-mouth disease virus antagonizes NOD2-mediated antiviral effects by inhibiting NOD2 protein expression. J Virol. (2019) 93:e00124. doi: 10.1128/JVI.00124-19

75. Balachandran S, Roberts PC, Brown LE, Truong H, Pattnaik AK, Archer $\mathrm{DR}$, et al. Essential role for the dsRNA-dependent protein kinase PKR in innate immunity to viral infection. Immunity. (2000) 13:129-41. doi: 10.1016/S1074-7613(00)00014-5

76. Dar AC, Dever TE, Sicheri F. Higher-order substrate recognition of eIF2alpha by the RNA-dependent protein kinase PKR. Cell. (2005) 122:887900. doi: 10.1016/j.cell.2005.06.044

77. García MA, Meurs EF, Esteban M. The dsRNA protein kinase PKR: Virus and cell control. Biochimie. (2007) 89:799-811. doi: 10.1016/j.biochi.2007.03.001

78. Fan X, Han S, Yan D, Gao Y, Wei Y, Liu X, et al. Foot-and-mouth disease virus infection suppresses autophagy and NF- $\kappa \mathrm{B}$ antiviral responses via degradation of ATG5-ATG12 by 3C pro. Cell Death Dis. (2018) 8:e2561. doi: $10.1038 /$ cddis.2016.489

79. Fullam A, Schröder M. DExD/H-box RNA helicases as mediators of anti-viral innate immunity and essential host factors for viral replication. Biochim Biophys Acta Gene Regul Mech. (2013) 1829:854-65. doi: 10.1016/j.bbagrm.2013.03.012

80. Xue Q, Liu H, Zeng Q, Zheng H, Xue Q, Cai X. The DEAD-Box RNA Helicase DDX1 interacts with the viral protein 3D and inhibits foot-and-mouth disease virus replication. Virol Sin. (2019) 34:610-7. doi: 10.1007/s12250-019-00148-7

81. Lawrence P, Rieder E. Identification of RNA helicase A as a new host factor in the replication cycle of foot-and-mouth disease virus. J Virol. (2009) 83:11356-66. doi: 10.1128/JVI.02677-08

82. Wang D, Fang L, Li K, Zhong H, Fan J, Ouyang C, et al. Foot-and-mouth disease virus $3 \mathrm{C}$ protease cleaves NEMO to impair innate immune signaling. J Virol. (2012) 86:9311-22. doi: 10.1128/JVI.00722-12

83. Wang D, Fang L, Luo R, Ye R, Fang Y, Xie L, et al. Foot-andmouth disease virus leader proteinase inhibits dsRNA-induced type I interferon transcription by decreasing interferon regulatory factor $3 / 7$ in protein levels. Biochem Biophys Res Commun. (2010) 399:72-8. doi: 10.1016/j.bbrc.2010.07.044

84. Liu J, Qian C, Cao X. Post-translational modification control of innate immunity. Immunity. (2016) 45:15-30. doi: 10.1016/j.immuni.2016. 06.020

85. Wang D, Fang L, Li P, Sun L, Fan J, Zhang Q, et al. The leader proteinase of foot-and-mouth disease virus negatively regulates the type I interferon pathway by acting as a viral deubiquitinase. J Virol. (2011) 85:3758-66. doi: 10.1128/JVI.02589-10

86. Swatek KN, Aumayr M, Pruneda JN, Visser LJ, Berryman S, Kueck AF, et al. Irreversible inactivation of ISG15 by a viral leader protease enables alternative infection detection strategies. Proc Natl Acad Sci USA. (2018) 115:2371-6. doi: 10.1073/pnas.1710617115

87. Medina GN, Azzinaro P, Ramirez-Medina E, Gutkoska J, Fang Y, DiazSan Segundo F, et al. Impairment of the deISGylation activity of FMDV Lpro causes attenuation in vitro and in vivo. J Virol. (2020) 94:e00341-20. doi: 10.1128/JVI.00341-20

88. Du Y, Bi J, Liu J, Liu X, Wu X, Jiang P, et al. $3 C^{\text {pro }}$ of foot-andmouth disease virus antagonizes the interferon signaling pathway by blocking STAT1/STAT2 nuclear translocation. J Virol. (2014) 88:4908-20. doi: 10.1128/JVI.03668-13

89. Li D, Wei J, Yang F, Liu H-N, Zhu Z-X, Cao W-J, et al. Foot-andmouth disease virus structural protein VP3 degrades Janus kinase 1 to inhibit IFN- $\gamma$ signal transduction pathways. Cell Cycle. (2016) 15:850-0. doi: 10.1080/15384101.2016.1151584

90. Wang J, Wang Y, Liu J, Ding L, Zhang Q, Li X, et al. A critical role of $\mathrm{N}$-myc and STAT interactor (Nmi) in foot-and-mouth disease virus (FMDV) 2C-induced apoptosis. Virus Res. (2012) 170:59-65. doi: 10.1016/j.virusres.2012.08.018

91. Šinkora M, Šinkorová J, Holtmeier W. Development of $\gamma \delta$ thymocyte subsets during prenatal and postnatal ontogeny. Immunology. (2005) 115:544-55. doi: 10.1111/j.1365-2567.2005.02194.x 
92. Boysen P, Olsen I, Berg I, Kulberg S, Johansen GM, Storset AK. Bovine CD2/NKp46+ cells are fully functional natural killer cells with a high activation status. BMC Immunol. (2006) 7:10. doi: 10.1186/1471-2172-7-10

93. Boysen P, Klevar S, Olsen I, Storset AK. The protozoan Neospora caninum directly triggers bovine NK cells to produce gamma interferon and to kill infected fibroblasts. Infect Immun. (2006) 74:953-60. doi: 10.1128/IAI.74.2.953-960.2006

94. Denyer MS, Wileman TE, Stirling CMA, Zuber B, Takamatsu HH. Perforin expression can define CD8 positive lymphocyte subsets in pigs allowing phenotypic and functional analysis of natural killer, cytotoxic T, natural killer $\mathrm{T}$ and MHC un-restricted cytotoxic T-cells. Vet Immunol Immunopathol. (2006) 110:279-92. doi: 10.1016/j.vetimm.2005.10.005

95. Swiecki M, Colonna M. The multifaceted biology of plasmacytoid dendritic cells. Nat Rev Immunol. (2015) 15:471-85. doi: 10.1038/nri3865

96. Toka FN, Nfon C, Dawson H, Golde WT. Natural killer cell dysfunction during acute infection with foot-and-mouth disease virus. Clin Vaccine Immunol. (2009) 16:1738-49. doi: 10.1128/CVI.00280-09

97. Díaz-San Segundo F, Rodríguez-Calvo T, de Avila A, Sevilla N. Immunosuppression during acute infection with foot-and-mouth disease virus in swine is mediated by IL-10. PLoS ONE. (2009) 4:e5659. doi: 10.1371/journal.pone.0005659

98. Nfon CK, Ferman GS, Toka FN, Gregg DA, Golde WT. Interferon-alpha production by swine dendritic cells is inhibited during acute infection with foot-and-mouth disease virus. Viral Immunol. (2008) 21:68-77. doi: 10.1089/vim.2007.0097

99. Guzylack-Piriou L, Balmelli C, Mccullough KC, Summerfield A. Type-A CpG oligonucleotides activate exclusively porcine natural interferon-producing cells to secrete interferon- $\alpha$, tumour necrosis factor- $\alpha$ and interleukin-12. Immunology. (2004) 112:28-37. doi: 10.1111/j.1365-2567.2004.01856.x

100. Guzylack-Piriou L, Bergamin F, Gerber M, McCullough KC, Summerfield A. Plasmacytoid dendritic cell activation by foot-and-mouth disease virus requires immune complexes. Eur J Immunol. (2006) 36:1674-83. doi: 10.1002/eji.200635866

101. Nfon CK, Toka FN, Kenney M, Pacheco JM, Golde WT. Loss of plasmacytoid dendritic cell function coincides with lymphopenia and viremia during foot-and-mouth disease virus infection. Viral Immunol. (2010) 23:29-41. doi: 10.1089/vim.2009.0078

102. Bautista EM, Ferman GS, Gregg D, Brum MCS, Grubman MJ, Golde WT. Constitutive expression of alpha interferon by skin dendritic cells confers resistance to infection by foot-and-mouth disease virus. J Virol. (2005) 79:4838-47. doi: 10.1128/JVI.79.8.4838-4847.2005

103. Rigden RC, Carrasco CP, Summerfield A, McCullough KC. Macrophage phagocytosis of foot-and-mouth disease virus may create infectious carriers. Immunology. (2002) 106:537-48. doi: 10.1046/j.1365-2567.2002. 01460.x

104. Takamatsu H-H, Denyer MS, Stirling C, Cox S, Aggarwal N, Dash P, et al. Porcine gammadelta $\mathrm{T}$ cells: possible roles on the innate and adaptive immune responses following virus infection. Vet Immunol Immunopathol. (2006) 112:49-61. doi: 10.1016/j.vetimm.2006.03.011

105. Patch JR, Dar PA, Waters R, Toka FN, Barrera J, Schutta C, et al. Infection with foot-and-mouth disease virus (FMDV) induces a natural killer (NK) cell response in cattle that is lacking following vaccination. Comp Immunol Microbiol Infect Dis. (2014) 37:249-57. doi: 10.1016/j.cimid.2014.07.004

106. Sei JJ, Waters RA, Kenney M, Barlow JW, Golde WT. Effect of foot-andmouth disease virus infection on the frequency, phenotype and function of circulating dendritic cells in cattle. PLOS ONE. (2016) 11:e0152192. doi: 10.1371/journal.pone.0152192

107. Toka FN, Kenney MA, Golde WT. Rapid and transient activation of $\mathrm{T}$ Cells to IFN- production, NK cell-like killing, and antigen processing during acute virus infection. J Immunol. (2011) 186:4853-61. doi: 10.4049/jimmunol.1003599

108. Diaz-San Segundo F, Salguero FJ, de Avila A, Fernandez de Marco MM, Sanchez-Martin MA, Sevilla N. Selective lymphocyte depletion during the early stage of the immune response to foot-and-mouth disease virus infection in swine. J Virol. (2006) 80:2369-79. doi: 10.1128/JVI.80.5.2369-2379. 2006
109. Zhang Z, Ahmed R, Paton D, Bashiruddin JB. Cytokine mRNA responses in bovine epithelia during foot-and-mouth disease virus infection. Vet J. (2009) 179:85-91. doi: 10.1016/j.tvjl.2007.08.012

110. Arzt J, Pacheco JM, Smoliga GR, Tucker MT, Bishop E, Pauszek SJ, et al. Foot-and-mouth disease virus virulence in cattle is co-determined by viral replication dynamics and route of infection. Virology. (2014) 452-453:12-22. doi: 10.1016/j.virol.2014.01.001

111. Stenfeldt C, Arzt J, Pacheco JM, Gladue DP, Smoliga GR, Silva EB, et al. A partial deletion within foot-and-mouth disease virus non-structural protein $3 \mathrm{~A}$ causes clinical attenuation in cattle but does not prevent subclinical infection. Virology. (2018) 516:115-26. doi: 10.1016/j.virol.2018.01.008

112. Stenfeldt C, Eschbaumer M, Pacheco JM, Rekant SI, Rodriguez LL, Arzt J. Pathogenesis of primary foot-and-mouth disease virus infection in the nasopharynx of vaccinated and non-vaccinated cattle. PLOS ONE. (2015) 10:e0143666. doi: 10.1371/journal.pone.0143666

113. Dinter Z, Philipson L. An interferon produced by Foot and Mouth Disease Virus (FMDV) in calf kidney cells. Proc Soc Exp Biol Med. (1962) 109:893-7. doi: 10.3181/00379727-109-27370

114. Richmond JY. An interferon-like inhibitor of foot-and-mouth disease virus induced by phytohemagglutinin in swine leukocyte culturesb. Arch Gesamte Virusforsch. (1969) 27:282-9. doi: 10.1007/BF01249650

115. Chinsangaram J, Piccone ME, Grubman MJ. Ability of foot-andmouth disease virus to form plaques in cell culture is associated with suppression of alpha/beta interferon. J Virol. (1999) 73:9891-8. doi: 10.1128/JVI.73.12.9891-9898.1999

116. Grubman MJ, Diaz-San Segundo F, Dias CC, Moraes M, Perez-Martin E, de Los Santos T. Use of replication-defective adenoviruses to develop vaccines and biotherapeutics against foot-and-mouth disease. Future Virol. (2012) 7:12. doi: $10.2217 /$ fvl.12.65

117. Walker AM, Roberts RM. Characterization of the bovine type I IFN locus: rearrangements, expansions, and novel subfamilies. BMC Genomics. (2009) 10:187. doi: 10.1186/1471-2164-10-187

118. Sang Y, Rowland RRR, Hesse RA, Blecha F. Differential expression and activity of the porcine type I interferon family. Physiol Genomics. (2010) 42:248-58. doi: 10.1152/physiolgenomics.00198.2009

119. Shields LE, Jennings J, Liu Q, Lee J, Ma W, Blecha F, et al. Crossspecies genome-wide analysis reveals molecular and functional diversity of the unconventional interferon- $\omega$ subtype. Front Immunol. (2019) 10:1431. doi: 10.3389/fimmu.2019.01431

120. Zhao X, Cheng G, Yan W, Liu M, He Y, Zheng Z. Characterization and virusinduced expression profiles of the porcine interferon- $\omega$ multigene family. $J$ Interf Cytokine Res. (2009) 29:687-93. doi: 10.1089/jir.2008.0060

121. Sang Y, Bergkamp J, Blecha F. Molecular evolution of the porcine type I interferon family: Subtype-specific expression and antiviral activity. PLoS ONE. (2014) 9:e112378. doi: 10.1371/journal.pone.0112378

122. Martal JL, Chêne NM, Huynh LP, L'Haridon RM, Reinaud PB, Guillomot MW, et al. IFN-tau: a novel subtype I IFN1. Structural characteristics, non-ubiquitous expression, structure-function relationships, a pregnancy hormonal embryonic signal and cross-species therapeutic potentialities. Biochimie. (1998) 80:755-77. doi: 10.1016/S0300-9084(99)80029-7

123. Wheelock EF. Interferon-like virus-inhibitor induced in human leukocytes by phytohemagglutinin. Science. (1965) 149:310-1. doi: $10.1126 /$ science.149.3681.310

124. Billiau A, Matthys P. Interferon- $\gamma$ : a historical perspective. Cytok Growth Factor Rev. (2009) 20:97-113. doi: 10.1016/j.cytogfr.2009.02.004

125. Parida S, Oh Y, Reid SM, Cox SJ, Statham RJ, Mahapatra M, et al. Interferon$\gamma$ production in vitro from whole blood of foot-and-mouth disease virus (FMDV) vaccinated and infected cattle after incubation with inactivated FMDV. Vaccine. (2006) 24:964-9. doi: 10.1016/j.vaccine.2005.08.108

126. Bucafusco D, Di Giacomo S, Pega J, Schammas JM, Cardoso N, Capozzo $\mathrm{AV}$, et al. Foot-and-mouth disease vaccination induces cross-reactive IFN$\gamma$ responses in cattle that are dependent on the integrity of the $140 \mathrm{~S}$ particles. Virology. (2015) 476:11-8. doi: 10.1016/j.virol.2014.11.023

127. Sharma AK, Bhatt M, Sankar M, Mohapatra JK, Dash BB, Gowane GR, et al. Kinetics of interferon gamma and interleukin-21 response following foot and mouth disease virus infection. Microb Pathog. (2018) 125:20-5. doi: 10.1016/j.micpath.2018.08.049 
128. Oh Y, Fleming L, Statham B, Hamblin P, Barnett P, Paton DJ, et al. Interferon$\gamma$ induced by in vitro re-stimulation of CD4+ T-cells correlates with in vivo FMD vaccine induced protection of cattle against disease and persistent infection. PLoS ONE. (2012) 7:e44365. doi: 10.1371/journal.pone.0044365

129. Fu Y, Zhu Z, Chang $\mathrm{H}$, Liu Z, Liu J, Chen H. Comparative transcriptome analyses indicate enhanced cellular protection against FMDV in PK15 cells pretreated with IFN- $\gamma$. Gene. (2016) 586:206-15. doi: 10.1016/j.gene.2016.03.027

130. Odendall C, Kagan JC. The unique regulation and functions of type III interferons in antiviral immunity. Curr Opin Virol. (2015) 12:47-52. doi: 10.1016/j.coviro.2015.02.003

131. Qin XQ, Tao N, Dergay A, Moy P, Fawell S, Davis A, et al. Interferon-beta gene therapy inhibits tumor formation and causes regression of established tumors in immune-deficient mice. Proc Natl Acad Sci USA. (1998) 95:144116. doi: 10.1073/pnas.95.24.14411

132. Lukaszewski RA, Brooks TJG. Pegylated alpha interferon is an effective treatment for virulent venezuelan equine encephalitis virus and has profound effects on the host immune response to infection. J Virol. (2000) 74:5006-15. doi: 10.1128/JVI.74.11.5006-5015.2000

133. Santodonato L, Ferrantini M, Palombo F, Aurisicchio L, Delmastro P, La Monica N, et al. Antitumor activity of recombinant adenoviral vectors expressing murine IFN-alpha in mice injected with metastatic IFN-resistant tumor cells. Cancer Gene Ther. (2001) 8:63-72. doi: 10.1038/sj.cgt.7700274

134. Fried MW, Shiffman ML, Rajender Reddy K, Smith C, Marinos G, Gonçales FL, et al. Peginterferon alfa-2a plus ribavirin for chronic hepatitis $\mathrm{C}$ virus infection. N Engl J Med. (2002) 347:975-82. doi: 10.1056/NEJMoa020047

135. Woo ASJ, Kwok R, Ahmed T. Alpha-interferon treatment in hepatitis B. Ann Transl Med. (2017) 5:159. doi: 10.21037/atm.2017.03.69

136. Ortiz MA, Espino-Paisan L, Nunez C, Alvarez-Lafuente R, Urcelay E. New life to an old treatment: pegylated interferon beta la in the management of multiple sclerosis. Curr Med Chem. (2018) 25:3272-83. doi: 10.2174/0929867325666180226105612

137. Guo J, Xiao Y, Iyer R, Lu X, Lake M, Ladror U, et al. Empowering therapeutic antibodies with IFN- $\alpha$ for cancer immunotherapy. PLoS ONE. (2019) 14:e0219829. doi: 10.1371/journal.pone.0219829

138. Domingo E, Escarmís C, Baranowski E, Ruiz-Jarabo CM, Carrillo E, Núñez JI, et al. Evolution of foot-and-mouth disease virus. Virus Res. (2003) 91:4763. doi: 10.1016/S0168-1702(02)00259-9

139. Alexandersen S, Zhang Z, Donaldson AI, Garland AJ. The pathogenesis and diagnosis of foot-and-mouth disease. J Comp Pathol. (2003) 129:1-36. doi: 10.1016/S0021-9975(03)00041-0

140. Pacheco JM, Arzt J, Rodriguez LL. Early events in the pathogenesis of footand-mouth disease in cattle after controlled aerosol exposure. Vet J. (2010) 183:46-53. doi: 10.1016/j.tvjl.2008.08.023

141. Pacheco JM, Tucker M, Hartwig E, Bishop E, Arzt J, Rodriguez LL. Direct contact transmission of three different foot-and-mouth disease virus strains in swine demonstrates important strain-specific differences. Vet J. (2012) 193:456-63. doi: 10.1016/j.tvjl.2012.01.012

142. Fujita H, Asahina A, Tada Y, Fujiwara H, Tamaki K. Type I interferons inhibit maturation and activation of mouse langerhans cells. I Invest Dermatol. (2005) 125:126-33. doi: 10.1111/j.0022-202X.2005.23803.x

143. Salguero FJ, Sánchez-Martín MA, Díaz-San Segundo F, De Avila A, Sevilla N. Foot-and-mouth disease virus (FMDV) causes an acute disease that can be lethal for adult laboratory mice. Virology. (2005) 332:384-96. doi: 10.1016/j.virol.2004.11.005

144. Sommereyns C, Paul S, Staeheli P, Michiels T. IFN-lambda (IFN- $\lambda$ ) is expressed in a tissue-dependent fashion and primarily acts on epithelial cells in vivo. PLoS Pathog. (2008) 4:e1000017. doi: 10.1371/journal.ppat.1000017

145. Pulverer JE, Rand U, Lienenklaus S, Kugel D, Zietara N, Kochs G, et al. Temporal and spatial resolution of type I and III interferon responses in vivo. J Virol. (2010) 84:8626-38. doi: 10.1128/JVI.00303-10

146. McVicar JW, Richmond JY, Campbell CH, Hamilton LD. Observations of cattle, goats and pigs after administration of synthetic interferon inducers and subsequent exposure to foot and mouth disease virus. Can J Comp Med. (1973) 37:362-8.
147. Rodríguez-Pulido M, Borrego B, Sobrino F, Sáiz M. RNA structural domains in noncoding regions of the foot-and-mouth disease virus genome trigger innate immunity in porcine cells and mice. J Virol. (2011) 85:6492-501. doi: 10.1128/JVI.00599-11

148. Borrego B, Rodriguez-Pulido M, Mateos F, de la Losa N, Sobrino F, Saiz M. Delivery of synthetic RNA can enhance the immunogenicity of vaccines against foot-and-mouth disease virus (FMDV) in mice. Vaccine. (2013) 31:4375-81. doi: 10.1016/j.vaccine.2013. 07.008

149. Chen W, Liu M, Jiao Y, Yan W, Wei X, Chen J, et al. Adenovirusmediated RNA interference against foot-and-mouth disease virus infection both in vitro and in vivo. J Virol. (2006) 80:3559-66. doi: 10.1128/JVI.80.7.3559-3566.2006

150. Kim S-M, Lee K-N, Park J-Y, Ko Y-J, Joo Y-S, Kim H-S, et al. Therapeutic application of RNA interference against foot-and-mouth disease virus in vitro and in vivo. Antiviral Res. (2008) 80:178-84. doi: 10.1016/j.antiviral.2008.06.001

151. Belsham GJ, Normann P. Dynamics of picornavirus RNA replication within infected cells. J Gen Virol. (2008) 89:485-93. doi: 10.1099/vir.0.83385-0

152. Domingo E, Sheldon J, Perales C. Viral quasispecies evolution. Microbiol Mol Biol Rev. (2012) 76:159-216. doi: 10.1128/MMBR.05023-11

153. Kim S-M, Park J-H, Lee K-N, Kim S-K, Ko Y-J, Lee H-S, et al. Enhanced inhibition of foot-and-mouth disease virus by combinations of porcine interferon-alpha and antiviral agents. Antiviral Res. (2012) 96:213-20. doi: 10.1016/j.antiviral.2012.09.009

154. Pushko P, Parker M, Ludwig GV, Davis NL, Johnston RE, Smith JF. Replicon-helper systems from attenuated Venezuelan equine encephalitis virus: expression of heterologous genes in vitro and immunization against heterologous pathogens in vivo. Virology. (1997) 239:389-401. doi: 10.1006/viro.1997.8878

155. Konopka JL, Thompson JM, Whitmore AC, Webb DL, Johnston RE. Acute infection with venezuelan equine encephalitis virus replicon particles catalyzes a systemic antiviral state and protects from lethal virus challenge. $J$ Virol. (2009) 83:12432-42. doi: 10.1128/JVI.00564-09

156. Molinari P, García-Nuñez S, Gravisaco MJ, Carrillo E, Berinstein A, Taboga O. Baculovirus treatment fully protects mice against a lethal challenge of FMDV. Antiviral Res. (2010) 87:276-9. doi: 10.1016/j.antiviral.2010.05.008

157. Quattrocchi V, Molinari P, Langellotti C, Gnazzo V, Taboga O, Zamorano P. Co-inoculation of baculovirus and FMDV vaccine in mice, elicits very early protection against foot and mouth disease virus without interfering with long lasting immunity. Vaccine. (2013) 231:2713-18. doi: 10.1016/j.vaccine.2013.03.067

158. Wu Q, Brum MCS, Caron L, Koster M, Grubman MJ. Adenovirus-mediated type I interferon expression delays and reduces disease signs in cattle challenged with foot-and-mouth disease virus. J Interferon Cytok Res. (2003) 23:359-68. doi: 10.1089/107999003322226014

159. Pott J, Mahlakõiv T, Mordstein M, Duerr CU, Michiels T, Stockinger S, et al. IFN-lambda determines the intestinal epithelial antiviral host defense. Proc Natl Acad Sci USA. (2011) 108:7944-9. doi: 10.1073/pnas.1100552108

160. Su C, Duan X, Zheng J, Liang L, Wang F, Guo L. IFN- $\alpha$ as an adjuvant for adenovirus-vectored FMDV subunit vaccine through improving the generation of $\mathrm{T}$ follicular helper cells. PLOS ONE. (2013) 8:e66134. doi: 10.1371/journal.pone.0066134

Conflict of Interest: The authors declare that the research was conducted in the absence of any commercial or financial relationships that could be construed as a potential conflict of interest.

Copyright (C) 2020 Medina, de los Santos and Diaz-San Segundo. This is an openaccess article distributed under the terms of the Creative Commons Attribution License (CC BY). The use, distribution or reproduction in other forums is permitted, provided the original author(s) and the copyright owner(s) are credited and that the original publication in this journal is cited, in accordance with accepted academic practice. No use, distribution or reproduction is permitted which does not comply with these terms. 